\title{
Oxidized High-Density Lipoprotein Impairs Endothelial Progenitor Cells' Function by Activation of CD36-MAPK-TSP-1 Pathways
}

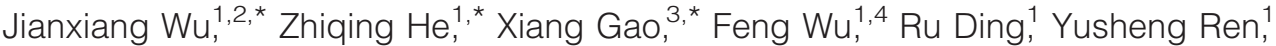 \\ Qijun Jiang, Min Fan, Chun Liang, and Zonggui $\mathrm{Wu}^{1}$
}

\begin{abstract}
Aims: High-density lipoprotein (HDL) levels inversely correlate with cardiovascular events due to the protective effects on vascular wall and stem cells, which are susceptible to oxidative modifications and then lead to potential pro-atherosclerotic effects. We proposed that oxidized HDL (ox-HDL) might lead to endothelial progenitor cells (EPCs) dysfunction and investigated underlying mechanisms. Results: ox-HDL was shown to increase apoptosis and intracellular reactive oxygen species levels, but to reduce migration, angiogenesis, and cholesterol efflux of EPCs in a dose-dependent manner. p38 mitogen-activated protein kinase (MAPK) and NF- $\kappa$ B were activated after ox-HDL stimulation, which also upregulated thrombospondin-1 (TSP-1) expression without affecting vascular endothelial growth factor. Effects caused by ox-HDL could be significantly attenuated by pretreatment with short hairpin RNA-mediated CD36 knockdown or probucol. Data of in vivo experiments and the inverse correlation of ox-HDL and circulating EPC numbers among patients with coronary artery diseases (CAD) or CAD and type 2 diabetes also supported it. Meanwhile, HDL separated from such patients could significantly increase cultured EPC's caspase 3 activity, further supporting our proposal. Innovation: This is the most complete study to date of how ox-HDL would impair EPCs function, which was involved with activation of CD36-p38 MAPK-TSP-1 pathways and proved by not only the inverse relationship between ox-HDL and circulating EPCs in clinic but also pro-apoptotic effects of HDL separated from patients' serum. Conclusion: Activation of CD36-p38 MAPK-TSP-1 pathways contributes to the pathological effects of ox-HDL on EPCs' dysfunction, which might be one of the potential etiological factors responsible for the disturbed neovascularization in chronic ischemic disease. Antioxid. Redox Signal. 22, 308-324.
\end{abstract}

\section{Introduction}

A NGIOGENESIS IS A VITAL COMPENSATORY response in chronic ischemic disease. Accumulating evidence suggests that circulating endothelial progenitor cells (EPCs) play a crucial role in this process $(51,60)$. Previous studies showed that the number of circulating EPCs was decreased and such cells' function was impaired in patients with atherosclerosis and diabetes $(63,71)$.

High-density lipoprotein (HDL) levels inversely correlate with cardiovascular events due to the protective effects on the vascular wall (5). Recent studies also demonstrated that HDL could directly stimulate EPCs differentiation and enhance ischemia-induced angiogenesis (58). However, a number of reports have indicated that HDL is susceptible to oxidation and structural modifications in case of atherosclerosis and diabetes $(13,15)$. Oxidized HDL (ox-HDL) not only might lose important protective functions but also acquire crucial pro-atherosclerosis properties (45). Previous studies suggested that ox-HDL might exert harmful effects on endothelial cells and platelet $(3,46)$. However, the effect of oxHDL on EPCs is still unclear.

\footnotetext{
Departments of ${ }^{1}$ Cardiology and ${ }^{3}$ Nephrology, Shanghai Changzheng Hospital, Second Military Medical University, Shanghai, People's Republic of China.

${ }^{2}$ Department of Geriatrics, No. 411 Hospital of People's Liberation Army, Shanghai, People's Republic of China.

${ }^{4}$ Department of Research, Center for Stem Cell Biology, Roger Williams Medical Center, Boston University School of Medicine, Providence, Rhode Island.

*Contributed equally to this work.
} 


\section{Innovation}

High-density lipoprotein (HDL) was the promising target for atherosclerosis in addition to low-density lipoprotein, but the failure of decreasing cardiovascular events proved by data from clinic studies aiming at increasing HDL levels in humans alerted us to focus on the ignored pathological effects of potential oxidative modification of HDL. Data from our study provided the mechanism of how oxidized HDL (ox-HDL) would impair endothelial progenitor cells (EPCs) function, which was involved with activation of CD36-p38 MAPK-TSP-1 pathways and also proved by the inverse relationship between ox-HDL and circulating EPCs in clinics.

CD36 was found to mediate the important communication between outside stimuli and the intracellular signal pathway in endothelial cells and phagocytes challenged with oxidized lipid $(30,32)$, and recently, studies uncover the modulative effects of CD36 in angiogenesis $(9,18)$, in which thrombospondin-1 (TSP-1) exerted negative effects via interaction with CD36. However, data from our previous studies and others $(27,62)$ showed that mitogen-activated protein kinase (MAPK) and NF- $\kappa$ B pathways played a key role in modulation of such cells' function. Based on the previous data, we investigated the effects of ox-HDL on EPCs and explored the potential signal pathways involving CD36-MAPK-TSP-1.

\section{Results}

\section{Characterization of human EPCs}

Human EPCs were cultured according to a protocol of endothelial colony-forming cells $(20,21)$, which could decrease potential loss of progenitor cells in blood and be more reliable and replicable compared with our previous protocol using density gradient centrifugation and then negative selection with magnetic microbeads (27). After 4 weeks' culture, the EPC colony became visible and such cells were first confirmed as cells that were double positive for acetylatedlow-density lipoprotein (ac-LDL) uptake and lectin (UEA-1) binding affinity (Fig. 1A). The colony formation assay showed that such cells at passage 2 could rapidly proliferate and form obvious colonies with a cobblestone-like morphology within a 4-day culture with endothelial cell growth medium-2 (EGM-2) (Fig. 1B). Meanwhile, Western blot results showed that endothelial nitric oxide synthase (eNOS) was expressed in such cells and human umbilical vein endothelial cells, but not in THP-1, which was in agreement with previous investigators (Fig. 1C) (29, 31). Expression profiles of such cells investigated by flow cytometry showed that they were positive for endothelial markers, such as CD34, CD31, CD105, CD73, KDR, CD146, and HLA-ADC, but negative for monocyte markers, such as CD14, CD45, CD133, CD90, and HLA-DR, which unequivocally confirmed such cells' endothelial identity (Fig. 1D). The more the homing and incorporation into neovascularization, characters of such cells were confirmed in a unilateral hind limb ischemia model based on athymic nude mice, which were transplanted into PKH26GL-labeled cells via tail vein injection (Fig. 1E). Everything that has been described earlier was consistent with previous studies about EPCs and confirmed the identity of EPCs $(21,49)$.
ox-HDL increased CD36 expression and promoted EPCs apoptosis

Since oxidized lipid was shown to lead to dysfunction of cells via CD36, so first Dil-labeled ox-HDL and AF488labeled CD36 antibody were added to the cultured EPCs to explore the potential interaction between them. As shown in Figure 2A, Dil-ox-HDL was co-localized with CD36, which implies that some interplay might exist. Then, EPCs were stimulated with different concentrations of ox-HDL $(0,10$, 20 , and $50 \mu \mathrm{g} / \mathrm{ml})$ and HDL $(50 \mu \mathrm{g} / \mathrm{ml})$. CD36 mRNA and protein expressions increased in a concentration-dependent pattern after being challenged with ox-HDL, whereas CD36 expression remained unchanged in HDL-treated EPCs (Fig. 2B, C). Nucleotransfection of EPCs with CD36-specific short hairpin RNA (shRNA) was shown to induce a greater than $70 \%$ reduction in CD36 transcript levels $(p<0.05$, Fig. 2), and a more than $60 \%$ in protein level (data not shown); while transfection of scramble shRNA did not influence CD36 mRNA and protein expression.

As shown in Figure 3A, ox-HDL significantly promoted EPCs apoptosis in a dose-dependent manner, which was similar to the CD36 expression pattern. Since CD36 was shown to mediate the inhibitory effects of oxidized lipoprotein such as oxidized low-density lipoprotein (ox-LDL) in monocytes (30), it was natural to infer that such pro-apoptotic effects of ox-HDL might be also mediated by CD36. shRNA-mediated knockdown of CD36 or probucol preincubation $(5 \mu M)$ could significantly attenuate the pro-apoptotic effects of ox-HDL $(p<0.05)$. Neither native HDL nor shRNA-mediated knockdown of CD36 alone could exert effects on EPC apoptosis (Fig. 3A).

\section{ox-HDL inhibited EPC migration and tube formation}

Migration and tube formation were very important for the corporation of EPCs into the injured arteries and angiogenesis in the ischemic tissues. As shown in Figure 3B and C, these functions of EPCs were significantly inhibited by oxHDL in a dose-dependent manner except in the $10 \mu \mathrm{g} / \mathrm{ml}$ group $(p<0.05)$, but these effects could be significantly attenuated by pretreatment with CD36 shRNA or probucol $(p<0.05)$. Although some trends toward promoting the cell's migration (transwell assay) and tube formation could be seen in the HDL group, no significant difference was shown by HDL $(p>0.05)$. Such results were different from a previous study (23) and could be attributed to the following points: (i) difference between HDL and EPCs used in our study and those in Huang's study, HDL and EPCs were separated from peripheral blood of healthy male volunteers who were on average aged 40, in our study, of which the relatively old volunteers from Huang's study could potentially negatively influence the beneficial effects of HDL and decrease the response of EPCs; (ii) different sensitivity of the assay used in our study, which showed that scratch wound-healing assay showed more promotive effects of HDL in EPC's migration compared with the control group $(p<0.05)$.

\section{ox-HDL increased intracellular reactive oxygen species levels in EPCs}

Since migration and tube formation of EPCs were shown to be negatively influenced by oxidative stress (66), and 
A
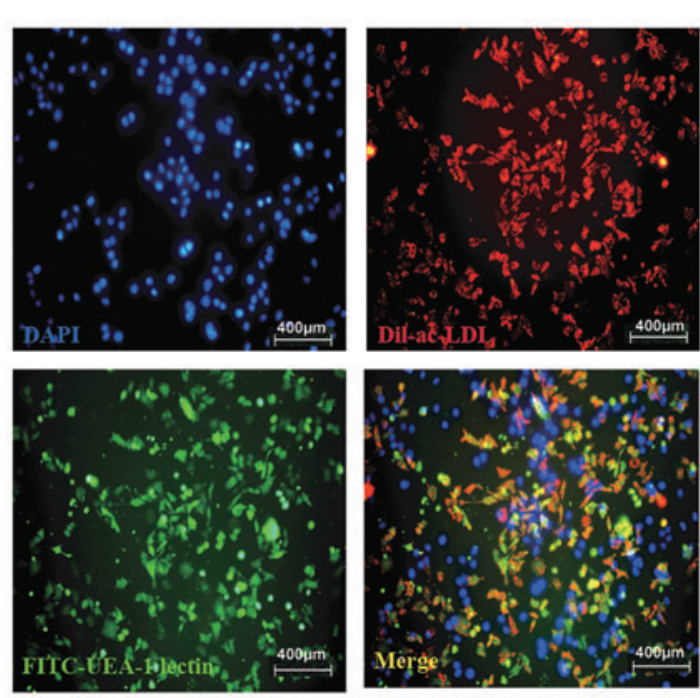

B
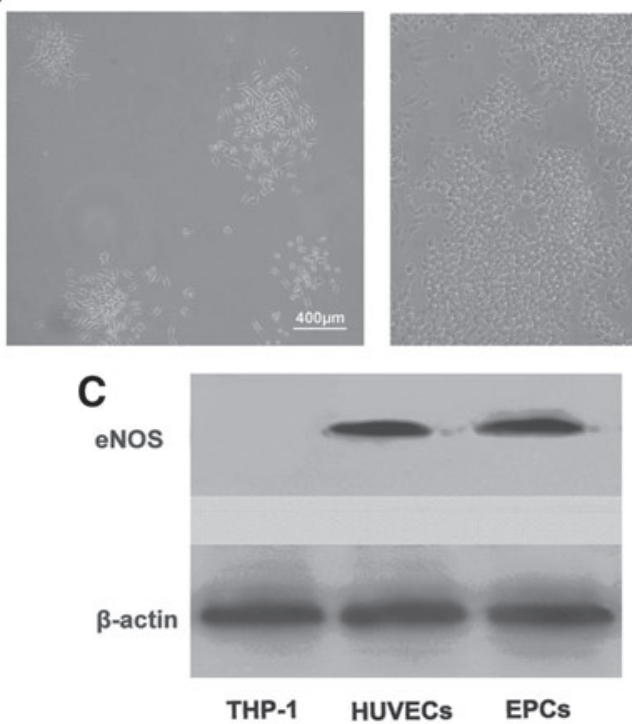

E
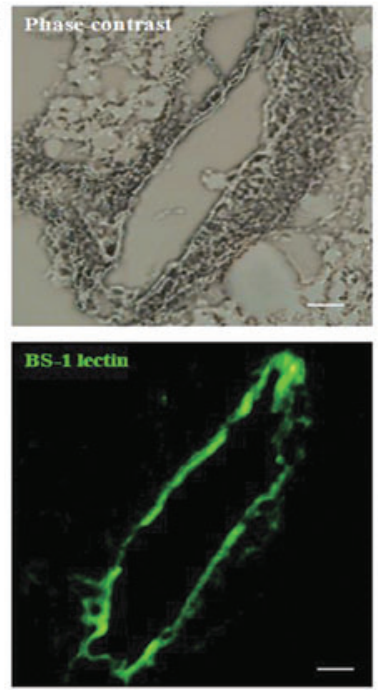

D4

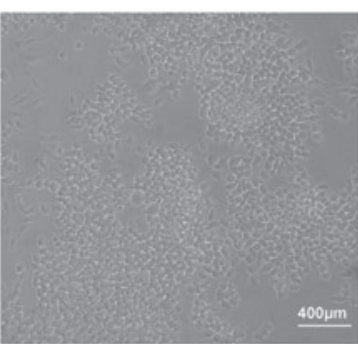

$400 \mathrm{~mm}$
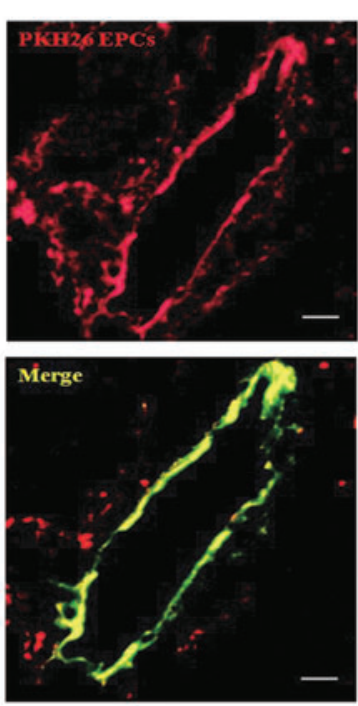

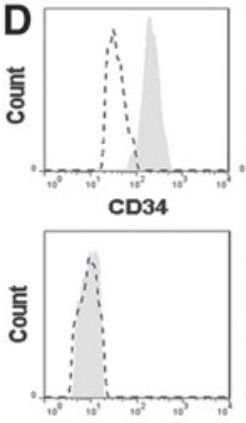

CD14

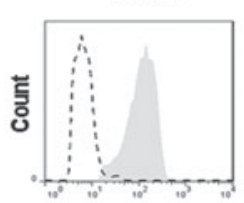

KDR
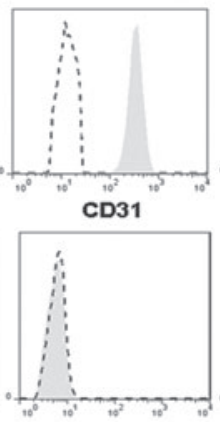

CD45

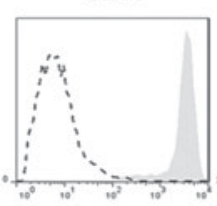

CD146
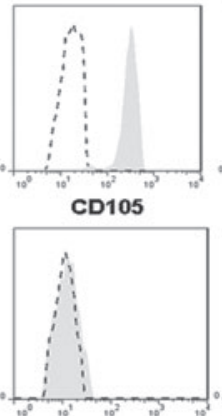

CD133

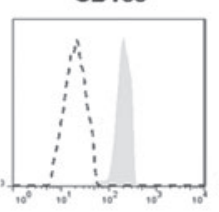

HLA-ABC
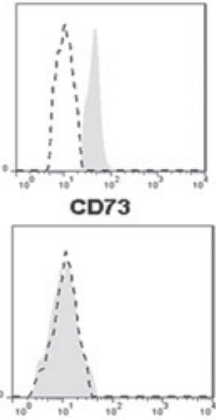

CD90

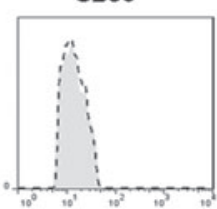

HLA-DR

FIG. 1. Characterization of EPCs by inverted fluorescence microscope, colony formation assay, Western blot, flow cytometry, and transplantation assay. (A) Double-positive cells with DAPI (blue), lectin binding (green), and Dil-ac-LDL uptake (red) captured by an Olympus IX5 inverted fluorescence microscope with Micropublisher 5.0 RTV imaging system appearing yellow in the overlay were identified as EPCs (Scale bar $=43 \mu \mathrm{m}$ ). (B) Cells of passage 2 were seeded in a sixwell culture plate at day 1 with EGM-2 medium, obvious colonies appeared, and cells were shown as a cobblestone-like morphology after 4-day culture. (C) Expression of eNOS in HUVECs, THP-1, and EPCs was detected by Western blot for which $\beta$-actin was used as an internal control. THP-1 and HUVECs were used as negative and positive controls, respectively. (D) Results of the cultured cell expression of different markers with flow cytometry. Positive cells are gated in gray, and isotype controls are in white. (E) Transplantated PKH26GL-prestained cells (red) were shown to home to injured artery and incorporate into the neovascularization after injection via the tail vein into athymic nude mice with unilateral hind limb ischemia, and the endothelial cells were stained with BS-1 lectin (green) injection into mice by a direct cardiac injection $($ Scale $\operatorname{bar}=50 \mu \mathrm{m})$. The representative data were from three experiments in triplicate. EGM-2, endothelial cell growth medium-2; eNOS, endothelial nitric oxide synthase; EPCs, endothelial progenitor cells.

ox-HDL was shown to induce oxidative stress in other cells (39), such effects could be mediated by CD36 (35); so, the intracellular reactive oxygen species (ROS) levels in EPCs were evaluated with a fluorescence microscope and quantified using Image J. After incubation with different concentrations of ox-HDL for $24 \mathrm{~h}$, intracellular ROS generation in EPCs was significantly increased compared with the control, scramble shRNA, CD36 shRNA, and HDL groups $(p<0.05)$, and such effects could be significantly inhibited by pretransfection of CD36 shRNA or probucol incubation $(p<0.05)$ (Fig. 3D). Intracellular ROS generation was similar between the native HDL-treated and control group $(p>0.05)$. Since several enzymes were proved to participate in maintaining the redox status and function of EPCs (19), the activity and mRNA expression of NADPH oxidase enzyme subunit NOX2 and CuZn SOD were chosen to be 
A

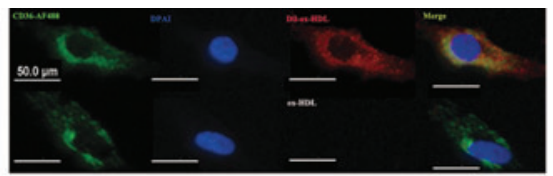

B

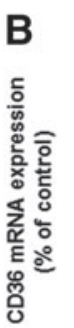

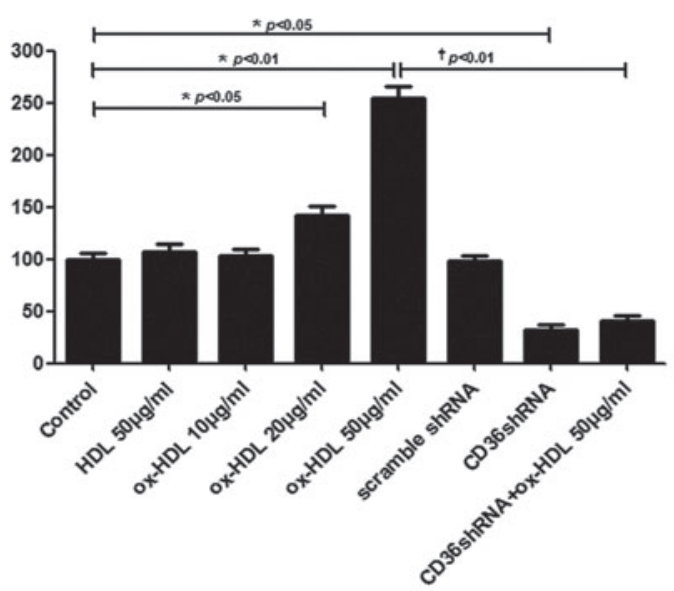

C
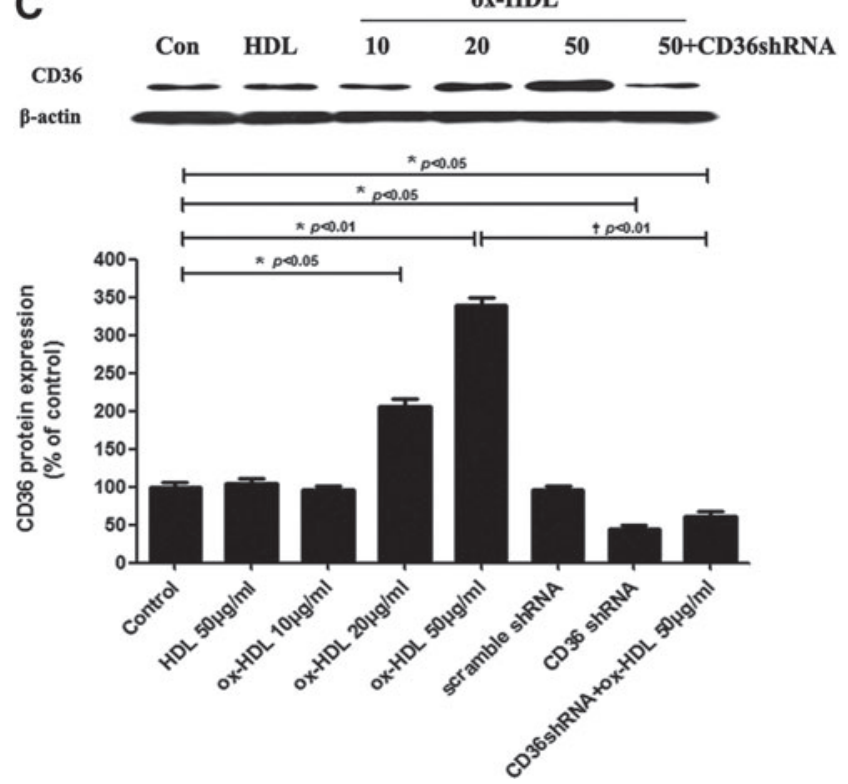

FIG. 2. Co-localization of ox-HDL and CD36 and effects of ox-HDL on CD36 expression in EPCs. EPCs were first incubated with either Dil-labeled or nonlabeled oxHDL (both at the concentration of $50 \mu \mathrm{g} / \mathrm{ml}$ ) for $8 \mathrm{~h}$; then, CD36 was stained with AF488-linked antibody and DAPI. After being fixed with $4 \%$ formaldehyde, images of colocalization of ox-HDL and CD36 were captured by an Olympus inverted fluorescent microscope with a DP71 digital camera and then analyzed using Image $\mathrm{J}$ software (A). Ox-HDL was shown to promote CD36 mRNA and protein expression in EPCs, which could be attenuated by shRNA-mediated knockdown. CD36 mRNA (B) and protein (C) expression of EPCs was investigated by real-time PCR and Western blot. Data are shown as means and standard errors, ${ }^{*} p<0.05$ versus control, ${ }^{\dagger} p<0.05$ versus $50 \mu \mathrm{g} / \mathrm{ml}$ ox-HDL. ox-HDL, oxidized high-density lipoprotein; PCR, polymerase chain reaction. investigated after being challenged with HDL or ox-HDL. Compared with the control and HDL, ox-HDL was found to increase activity of NADPH oxidase enzyme and copperzinc superoxide dismutase (CuZn SOD), upregulate NOX2 mRNA expression, but decrease NO production (Supplementary Fig. S1A-D; Supplementary Data are available online at www.liebertpub.com/ars), which was in agreement with a previous report about impaired function of HDL from patients with diabetes (56) and implied that eNOS uncoupling might participate in the pathological effects of ox-HDL.

\section{Expression of TSP-1 and VEGF modulated by ox-HDL}

TSP-1 and vascular endothelial growth factor (VEGF) are two major factors influencing angiogenesis, and the latter was shown to mediate the paracrine effects of EPCs. VEGF could promote angiogenesis, while TSP-1 was shown to exert the opposite effects via its receptor CD36 in microendothelial cells and EPCs $(9,70)$. So, the expression of VEGF and TSP1 in EPCs was investigated after challenge with ox-HDL in a hypoxic environment, which could maximally mimic the in vivo situation for the injected EPCs. TSP-1 mRNA and protein expressions of EPCs increased in a concentrationdependent manner after being challenged with ox-HDL for $24 \mathrm{~h}(p<0.05)$, which could be inhibited by pretransfection of CD36 shRNA or probucol preincubation $(p<0.05)$. While native HDL decreased TSP-1 expression only at mRNA level (Fig. 4A, C), native HDL and probucol but not ox-HDL promoted expression of VEGF compared with the control group $(p<0.05$, Fig. 4B, D).

\section{ox-HDL exerted negative effects on neovascularization, blood flow, and functional scoring of hind limb ischemia}

Angiographic results showed that transplantation of EPCs enhanced the vessel density compared with control animals injected with medium $(p<0.05)$. However, the vessel density after infusion of ox-HDL-stimulated EPCs was lower than that of mice injected with untreated EPCs and shRNAmediated knockdown of CD36 could block the pathological effects of ox-HDL $(p<0.05$, Fig. 5A, C). Similar effects on capillary density were confirmed by immunofluorescence analysis (Fig. 5A, D). In addition to neovascularization, the blood flow and functional scoring of hind limb ischemia was also evaluated by laser Doppler scanning and scales separately, which showed a similar trend with data of angiography and vessel density (Fig. 5A, B, E) and confirmed the inhibitory effects of ox-HDL on EPCs' function in vivo.

\section{Regulation of MAPK- NF-КB pathway by ox-HDL in EPCs}

Since MAPK family was confirmed to play an important role in the signal pathway mediated by activation of CD36 (7), the protein expression of MAPK family (p38, ERK, and JNK) was measured by Western blot to explore whether such phenomena also existed in EPCs challenged with ox-HDL. The expression of phosphor-p38 was significantly increased after incubating EPCs with ox-HDL in a dose-dependent manner $(p<0.05)$, which could be partially attenuated by shRNA-mediated CD36 knockdown in EPCs (Fig. 6A); while ox-HDL did not affect the expression of phosphor-ERK and 
A
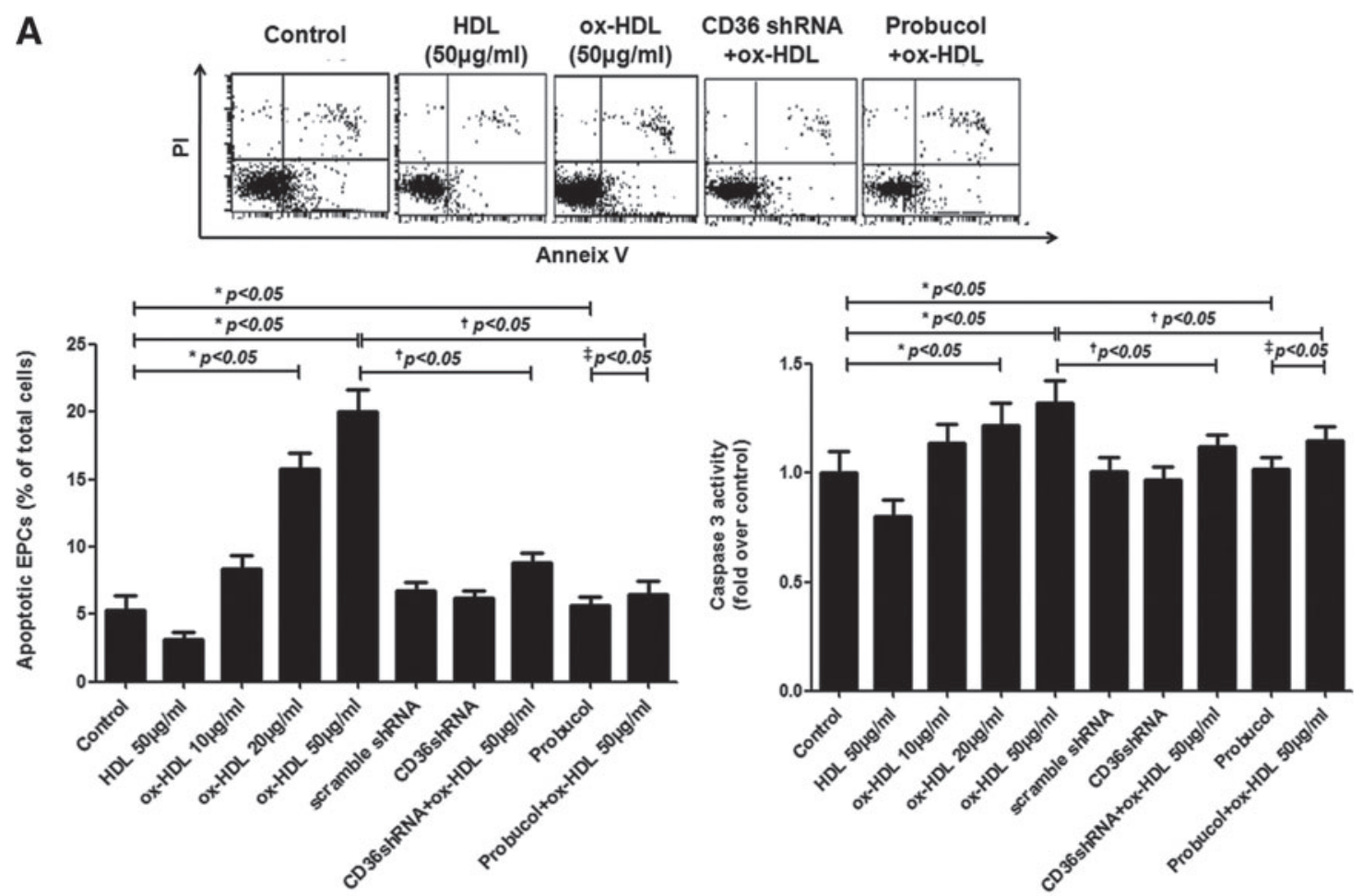

B
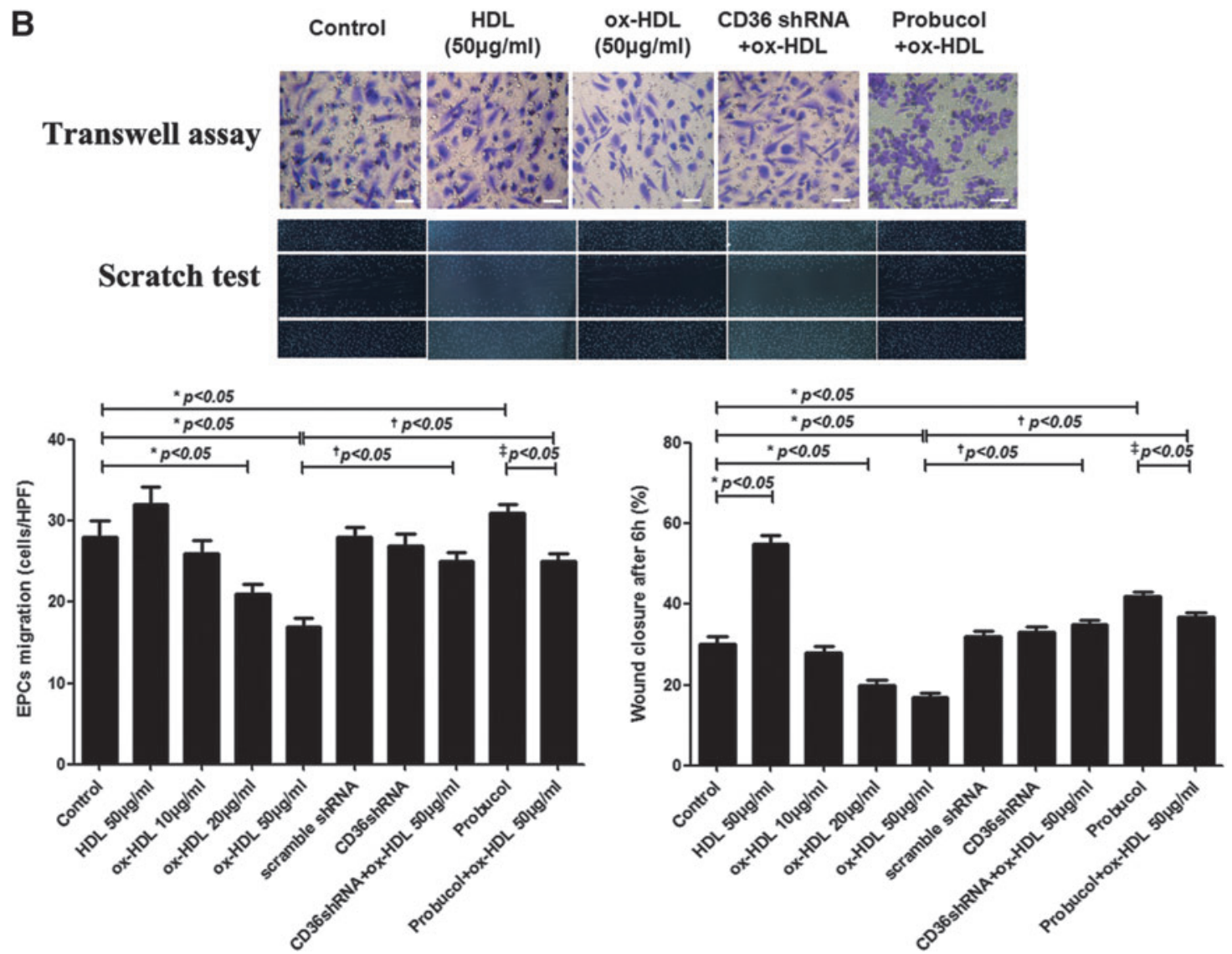

FIG. 3. Effects of ox-HDL on EPCs' function. ox-HDL was shown to impair EPCs' function, including apoptosis (A), migration (B), tube formation in Matrigel (C), and intracellular ROS generation (D) in a dose-dependent manner. Apoptosis was evaluated with flow cytometry and caspase 3 fluorimetric assay kit. Representative images showed migrated EPCs stained with hexamethyl pararosaniline in transwell assay or DAPI in scratch wound-healing assay (B), and intracellular ROS generation was evaluated with a fluorescence microscope. Pretreatment of EPCs with transfection with specific shRNA or probucol preincubation $(5 \mu M)$ could significantly inhibit such pathological effects. Data are shown as means and standard errors; ${ }^{*} p<0.05$ versus control, ${ }^{\dagger} p<0.05$ versus $50 \mu \mathrm{g} / \mathrm{ml}$ ox-HDL, and ${ }^{\ddagger} p<0.05$ versus $5 \mu M$ probucol. Four experiments were performed in triplicate (Scale bar $=100 \mu \mathrm{m}$ ). ROS, reactive oxygen species. 

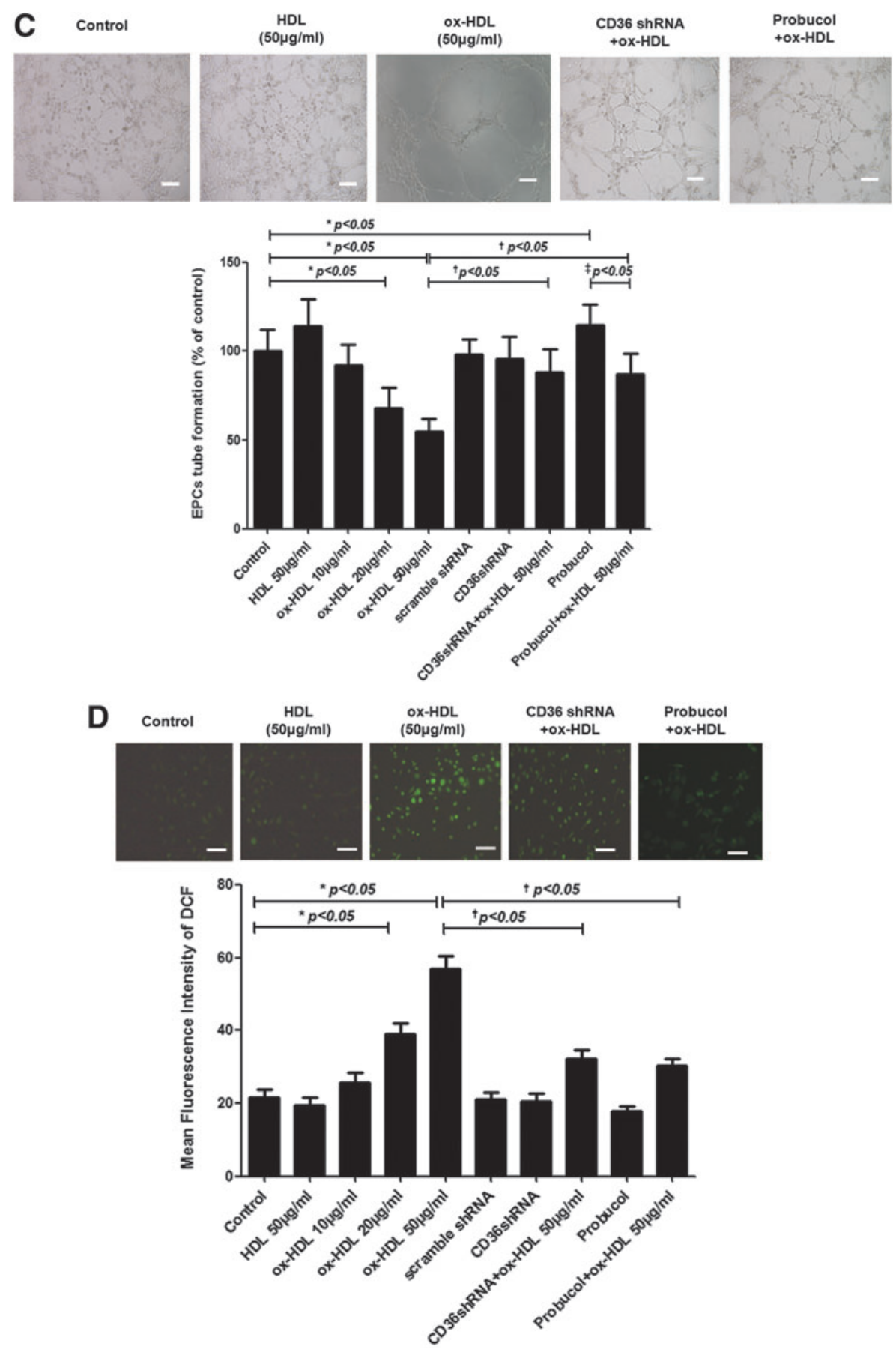

FIG. 3. (Continued).

JNK in EPCs (Fig. 6B, C). The electrophoretic mobility gel shift assay (EMSA) test showed that ox-HDL could increase the activity of NF- $\kappa \mathrm{B}$, which could be attenuated by shRNAmediated CD36 knockdown (Supplementary Fig. S2). While EPCs were pretreated with p38 or NF- $\kappa \mathrm{B}$-specific inhibitor before the challenge with ox-HDL, the inhibitory effects in migration and angiogenesis were significantly attenuated, which further support the role of activation of MAPK- NF- $\kappa \mathrm{B}$ pathway in ox-HDL-induced pathological effects on EPCs (Supplementary Fig. S3).

\section{Impairment of cholesterol efflux of EPCs by ox-HDL}

Our study showed that ox-HDL could induce dysfunction of EPCs, and data from previous experiments also confirmed that cultured macrophages could uptake ox-HDL, which then inhibit the cholesterol efflux out of cells; so, it needed to be confirmed whether such effects took place in EPCs exposed to ox-HDL. It was shown that ox-HDL would exert inhibitory effects on cholesterol efflux of EPCs, while shRNA-mediated knockdown CD36 could partly reverse such pathological 
A

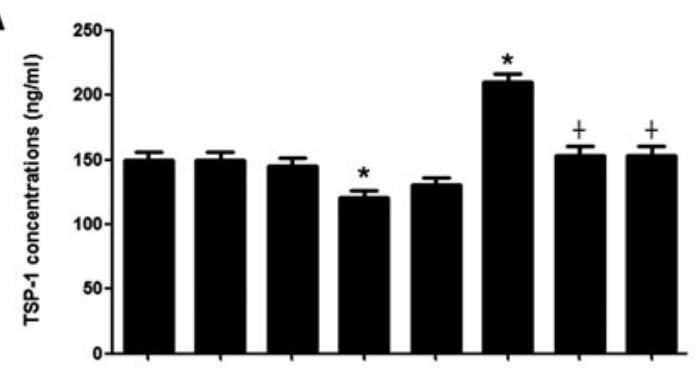

C

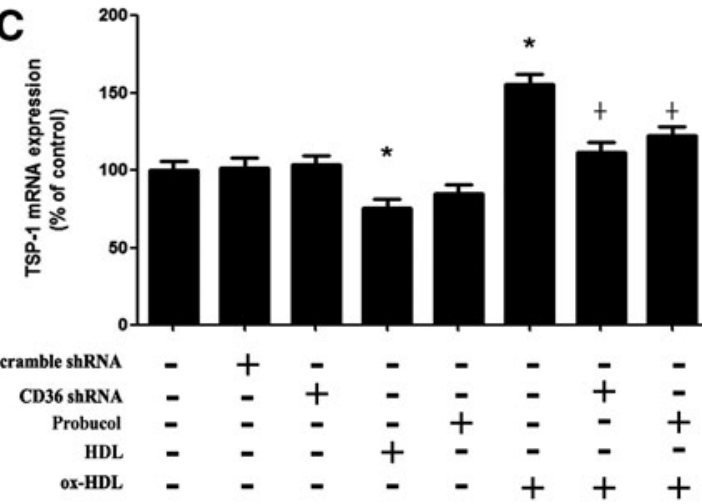

B

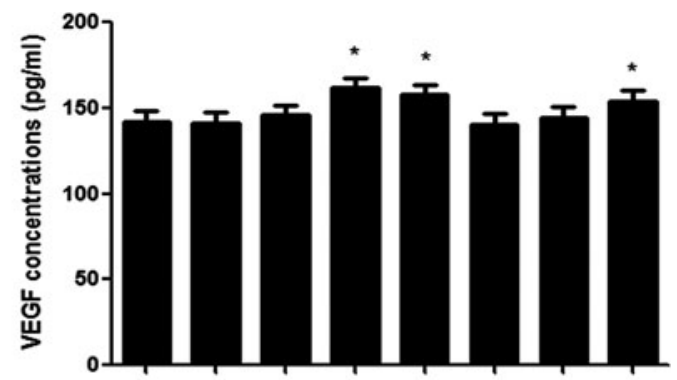

D

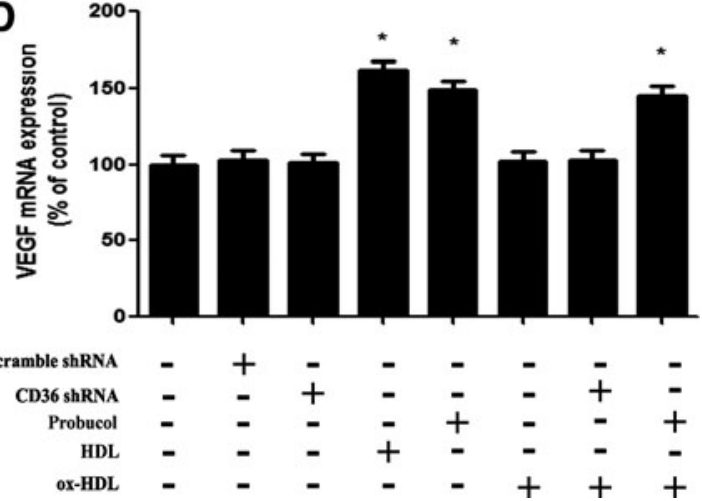

FIG. 4. Effects of ox-HDL on TSP-1 and VEGF expression in EPCs. ox-HDL would promote the expression of TSP-1 in a dose-dependent manner, while there was no significant difference between the control and ox-HDL-treated group and probucol could decrease the TSP-1 levels compared with ox-HDL group. Expression of TSP-1 (A) and VEGF (B) protein in EPCs detected by ELISA. Expression of TSP-1 (C) and VEGF (D) mRNA in EPCs detected by real-time PCR. Data are shown as means and standard errors; ${ }^{*} p<0.05$ versus control, and ${ }^{\dagger} p<0.05$ versus $50 \mu \mathrm{g} / \mathrm{ml}$ ox-HDL. These are the results of two experiments done in quadruplicate. ELISA, enzyme-linked immunosorbent assay; TSP-1, thrombospondin-1; VEGF, vascular endothelial growth factor.

effects, which was in accordance with the data from another study (Supplementary Fig. S4) (16).

\section{Negative correlation of $\mathrm{ox}-H D L$ and circulating EPCs countings}

Since data from both in vitro and in vivo experiments of ours and others confirmed the negative effects of ox-HDL on human EPCs, some correlation between ox-HDL and circulating EPCs might exist in clinic settings. In order to prove it, an observational clinical study was organized to investigate the potential correlation between them.

Characteristics of the 90 enrollers at the baseline are summarized in Table 1. As expected, patients with documented coronary artery disease (CAD) had significantly higher levels of C-reactive protein, body mass index, and triglyceride, lower level of HDL cholesterol and, more frequently, were treated with statins, anti-hypertension drugs, and platelet inhibitors. However, patients with CAD more commonly received statin treatment, which reflected that a low dose but not intense statin treatment was prevalent in China and slightly different from a previous report about European population (52). Using the modified International Society for Hematotherapy and Graft Engineering (ISHAGE) protocol, the numbers of $\mathrm{CD} 45^{\mathrm{dim}} \mathrm{CD} 34^{+} \mathrm{KDR}^{+}$cells were found to be significantly higher in healthy controls compared with those of patients with CAD $(0.055 \% \pm 0.010 \%$ vs. $0.022 \% \pm 0.011 \% / 100$ leukocytes, $p<0.05$ ) (Fig. 7A). While CD36 expression in cultured EPCs was shown to increase after challenging with ox-HDL, the mean fluorescence intensities (MFI) of CD36 in EPCs were detected by flow cytometry, which were higher in CAD patients than in healthy controls $(p<0.05)$ (Fig. 7B). The levels of thiobarbituric acid-reactive substances (TBARS) in serum were significantly higher among patients with CAD than those of healthy controls ( $1.328 \pm 0.330 v s .0 .768 \pm 0.220 \mu M, p<0.05)$, while the amount of TBARS in HDL exhibited a similar pattern between patients with CAD and healthy controls (264.174 \pm 74.731 vs. $181.435 \pm 75.798 \mathrm{n} M, p<0.05$ ) (Fig. 7C, D).

In addition to stable CAD patients, those with CAD and type 2 diabetes mellitus (DM) were also enrolled in the study, as previous reported data showed decreased levels and impaired function of EPCs in such a high-risk population for $\mathrm{CAD}(11,33,37)$. From the recorded fast glucose and HbA1c levels, such patients received a good management of blood glucose, which could significantly decrease potential interference caused by abnormal glucose metabolism. It was not surprising to find that a similar trend was seen in not only a decreased level of circulating EPCs $(0.021 \% \pm 0.010 \%$ vs. $0.055 \% \pm 0.010 \% / 100$ leukocytes, $p<0.05)$, but also an increased MFI of CD36 in EPCs, higher levels of TBARS in serum, and HDL compared with those of healthy controls (serum TBARS: $1.42 \pm 0.250$ vs. $0.768 \pm 0.220 \mu M, p<$ 0.05;HDL TBARS: $375 \pm 26.530 v s .181 .435 \pm 75.798 \mathrm{n} M$, $p<0.05)$. Levels of $\mathrm{CD} 45^{\mathrm{dim}} \mathrm{CD} 34^{+} \mathrm{KDR}^{+}$were shown to be inversely correlated with amounts of TBARS in serum $(R=-0.72, p<0.001, N=90)$ and in HDL $(R=-0.86, p<$ 0.001, $N=90$ ) (Fig. 7E, F). 
FIG. 5. Effects of ox-HDL on neovascularization in hind limb ischemia model based on athymic mice. (A) Representative photos of ischemic limbs, blood flow, and microangiography (the black arrows indicated the analyzed area). ${ }^{*} p<0.05$ versus control, ${ }^{\S} p<0.05$ versus post-operation flow ratio. Capillary density showed by immunofluorescence of CD31, which appeared in green. (B-E) The detailed data of blood flow ratio, angiographic score, capillary density, and Tarlov scores (functional scores of hind limb) of each group. Data are shown as means and standard errors; $* p<0.001$ versus control, ${ }^{\dagger} p<0.05$ versus untreated EPCs, and $p<0.05$ versus oxHDLpretreated EPCs (Scale bar $=120$ $\mu \mathrm{m})$. White bar represents control, gray bar represents EPC transplantation, black bar refers to transplantation of pretreatment of EPCs with ox-HDL, and dots bar means transplantation of EPCs transfected with shRNA aiming at decreasing CD36 before challenging with ox-HDL Representative data were derived from four experiments in triplicate.

A

After surgery
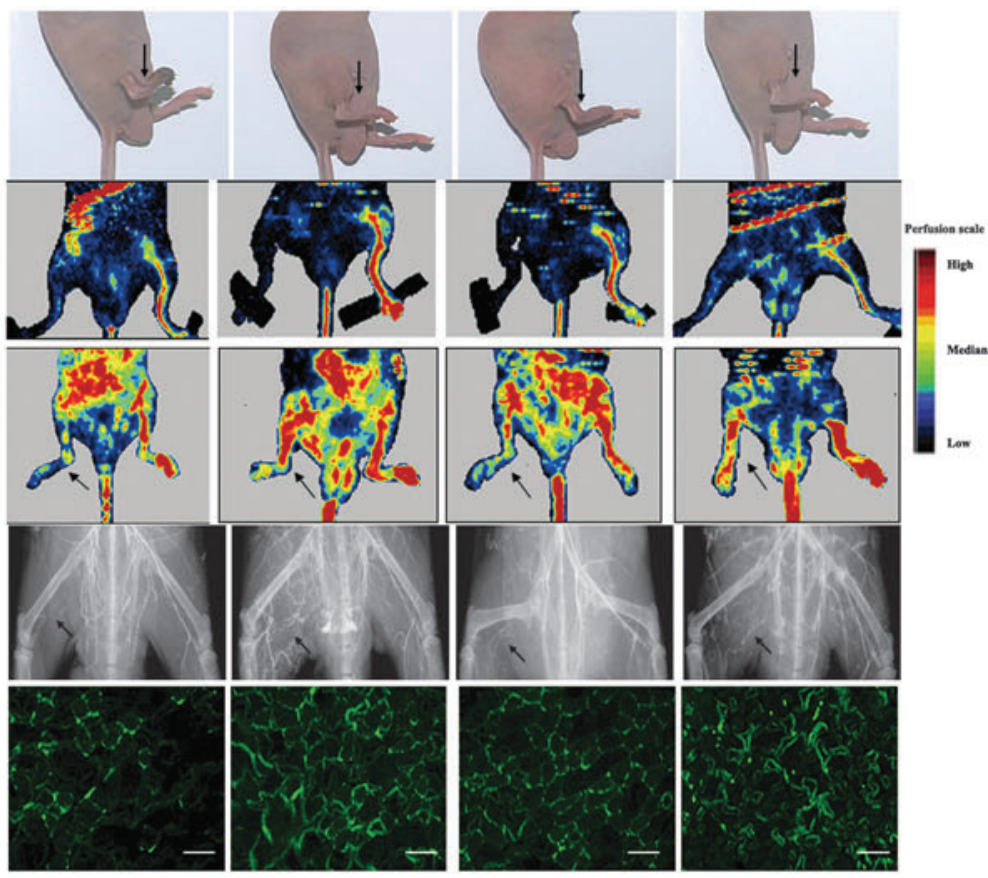

EPCs

ox-HDL
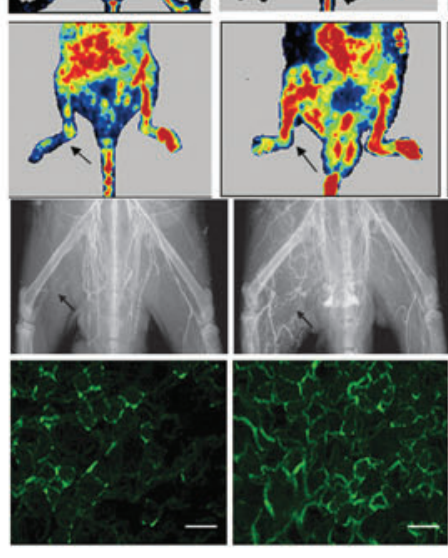

CD36shRNA

B

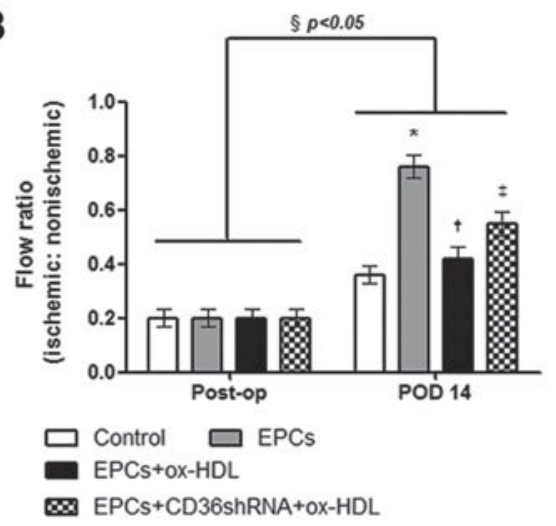

D

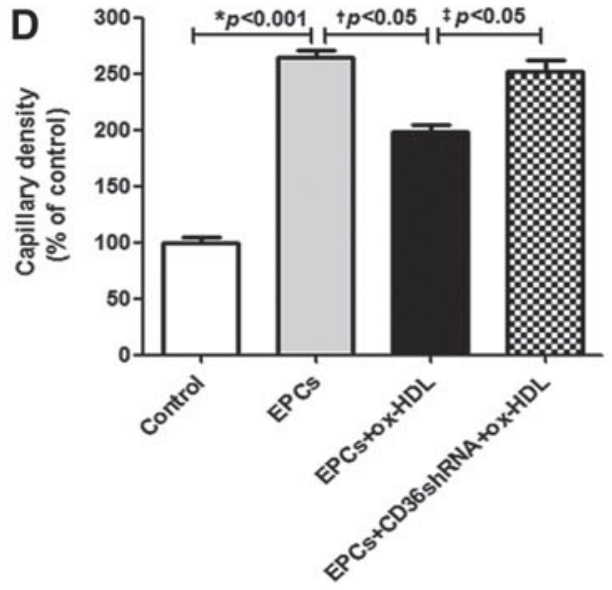

C

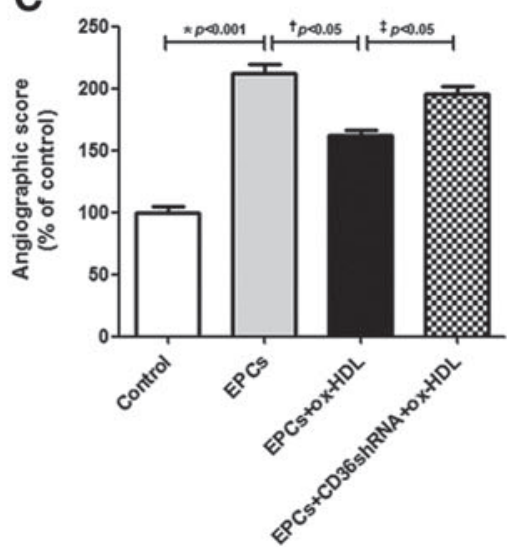

E

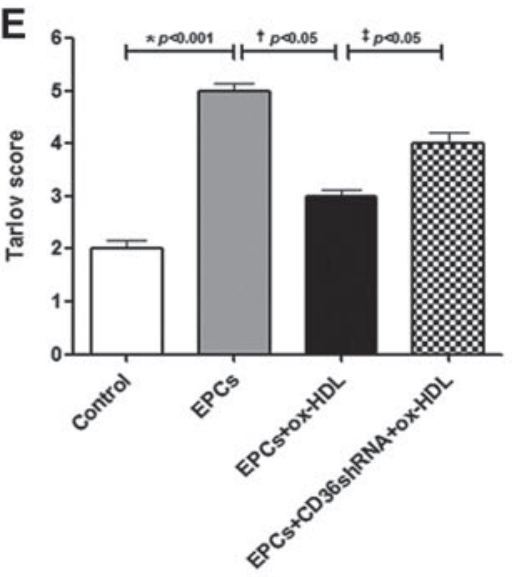


Since the negative correlation of ox-HDL and circulating EPCs levels was shown by the clinical study, HDL was separated from collected serum using ultracentrifugation among the enrolled healthy volunteers, CAD or CAD, and type 2 DM patients, and then added into EPCs' culture media at the final concentration of $50 \mu \mathrm{g} / \mathrm{ml}$ for $24 \mathrm{~h}$. HDL separated
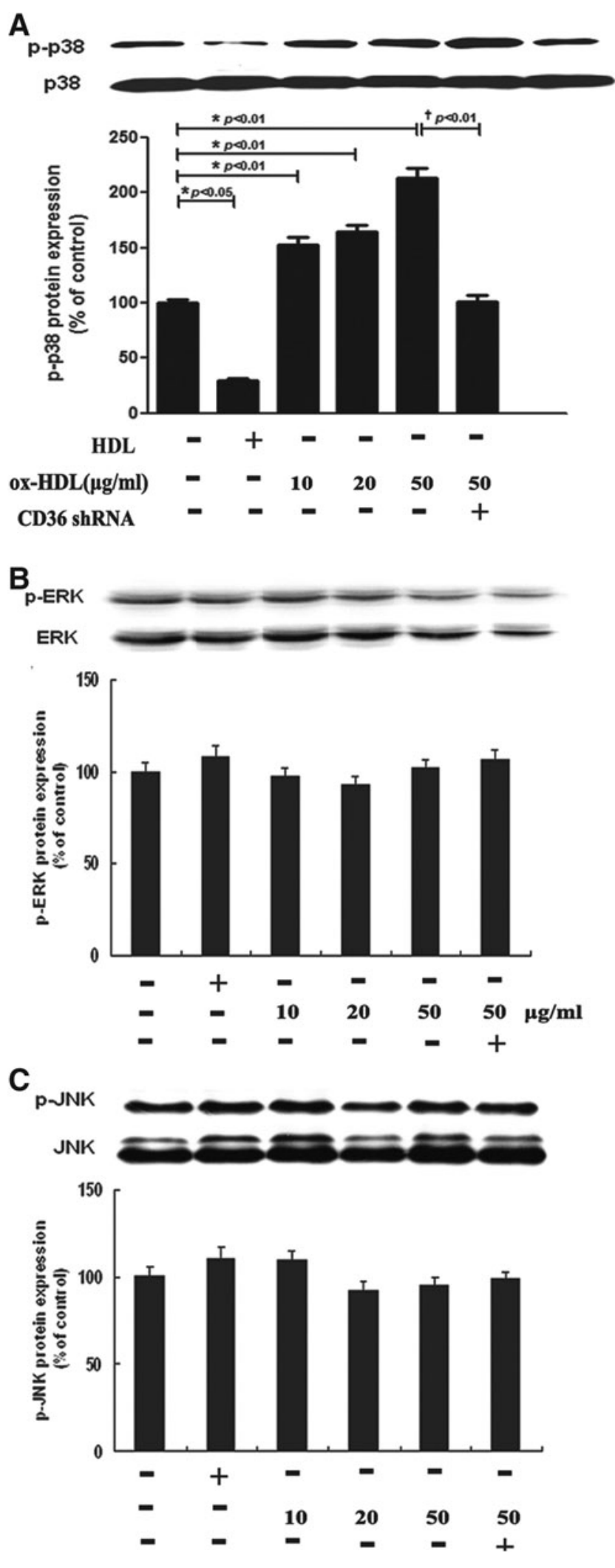

from CAD or CAD and DM patients showed pro-apoptotic effects of hEPCs compared with those from healthy volunteers, which was proved by increased caspase 3 activity and further confirmed the negative relationship between ox-HDL and circulating EPCs (Fig. 7G).

\section{Discussion}

High circulating levels of HDL are associated with a low risk for vascular disease (5), which could exert protective effects by reverse cholesterol transport, inhibition of adhesion molecule expression, and inhibition of LDL oxidation and increase endothelial nitric oxide production $(6,64)$. Recent studies indicated that HDL may directly stimulate differentiation of EPCs via phosphatidylinositol 3-kinase/Akt pathway and enhance ischemia-induced angiogenesis (58). However, cardioprotective functions of HDL are lost on oxidative damage and converted to pro-atherogenic effects by inhibiting nitric oxide synthesis, promoting production of ROS and platelet activation $(3,4,39)$. Oxidative modification of HDL could be achieved with copper ions or myeloperoxidase $(38,55)$, which differed in oxidation degree, change of active motifs, and related enzyme activity (43). Meanwhile, ox-LDL, as the similar lipid oxidative product and the most common risk factor of atherosclerosis, also showed similar effects on EPCs and lead to dysfunction of EPCs via activation of $\operatorname{CD} 36(67,75)$, but the molecular mechanism behind this might be different, considering the different composition and antioxidant effects of LDL and HDL; for example, the paraoxonase 1 activity of HDL (24), which was missing in LDL and deserved further experiments for comparison. In this study, the effects of ox-HDL on EPCs were investigated by incubation of EPCs with different concentrations of ox-HDL and to the best of our knowledge, this is the first report not only showing the deleterious effects of oxHDL on EPCs but also revealing the involved mechanism.

CD36, a member of scavenger receptor B family, is a transmembrane glycoprotein highly expressed by endothelial cells, monocytes/macrophages, platelets, and adipose tissue (12). It can bind to a variety of ligands, including ox-LDL, oxidized phospholipids, collagen, apoptotic cells, and TSP-1, a potent endogenous inhibitor of angiogenesis $(28,47)$. A recent study shows that CD36 is also a receptor for ox-HDL (65), which was in accordance with our study. The facts that ox-HDL-mediated pathological effects in EPCs' function could be blocked by shRNA-mediated CD36 knockdown support our proposal that CD36 played a key role in mediating the pathological effects of ox-HDL. In addition to CD36, it should be kept in mind that activation of immunerelated receptors such as toll-like receptors (TLRs) might

FIG. 6. Effects of ox-HDL on p38, ERK, and JNK phosphorylation of EPCs by Western blot analysis. Stimulation of EPCs with ox-HDL would increase phosphorylation of p38 MAPK, which was ameliorated by transfection of specific shRNA aiming at decreasing CD36, without changing the expression of phosphor-ERK and JNK (A-C). Data are shown as means and standard errors, ${ }^{*} p<0.05$ versus control, ${ }^{\dagger} p<0.01$ versus $50 \mu \mathrm{g} / \mathrm{ml}$ ox-HDL. Such data were from three experiments in triplicate. MAPK, mitogen-activated protein kinase. 
Table 1. Characteristics of the Study Population

\begin{tabular}{|c|c|c|c|}
\hline Characteristics & $\begin{array}{c}\text { Healthy } \\
\text { volunteers } \\
\mathrm{n}=30\end{array}$ & $\begin{array}{c}\text { Stable coronary } \\
\text { artery disease } \\
\mathrm{n}=30\end{array}$ & $\begin{array}{c}\text { CAD and type } 2 \\
\text { diabetes mellitus } \\
\mathrm{n}=30\end{array}$ \\
\hline \multicolumn{4}{|l|}{ Demographics, mean \pm SD } \\
\hline Age, years & $55 \pm 4$ & $56 \pm 3$ & $56 \pm 4$ \\
\hline Sex (male/female) & $15 / 15$ & $15 / 15$ & $15 / 15$ \\
\hline $\mathrm{BP}$ systolic, mmHg & $120.2 \pm 6.8$ & $124.4 \pm 11.2$ & $123.4 \pm 11.2$ \\
\hline $\mathrm{BP}$ diastolic, $\mathrm{mmHg}$ & $73.4 \pm 8.5$ & $78.2 \pm 9.5$ & $77.2 \pm 9.5$ \\
\hline BMI, $\mathrm{kg} / \mathrm{m}^{2}$ & $22 \pm 2$ & $26 \pm 3^{\mathrm{a}}$ & $25 \pm 3^{\mathrm{a}}$ \\
\hline \multicolumn{4}{|c|}{ Laboratory parameters, mean $\pm \mathrm{SD}$} \\
\hline Fasting glucose, $\mathrm{m} M$ & $5.7 \pm 1.4$ & $5.8 \pm 1.3$ & $6.5 \pm 1.6$ \\
\hline $\mathrm{HbA} 1 \mathrm{c}, \%$ & $5.6 \pm 0.5$ & $5.7 \pm 0.7$ & $6.3 \pm 0.35^{\mathrm{a}}$ \\
\hline Total cholesterol, $\mathrm{m} M$ & $5.5 \pm 0.6$ & $5.3 \pm 0.7$ & $6.5 \pm 0.6^{\mathrm{a}}$ \\
\hline HDL cholesterol, $\mathrm{m} M$ & $1.9 \pm 0.4$ & $1.2 \pm 0.5^{\mathrm{a}}$ & $1.0 \pm 0.3^{\mathrm{a}}$ \\
\hline LDL cholesterol, $\mathrm{m} M$ & $3.2 \pm 0.5$ & $3.5 \pm 0.3$ & $4.2 \pm 0.3^{\mathrm{a}}$ \\
\hline Triglyceride, $\mathrm{m} M$ & $0.8 \pm 0.3$ & $1.7 \pm 3.8^{\mathrm{a}}$ & $1.8 \pm 0.8^{\mathrm{a}}$ \\
\hline $\mathrm{CRP}, \mu M$ & $0.7 \pm 0.3$ & $2.7 \pm 0.8^{\mathrm{a}}$ & $3.5 \pm 0.7^{\mathrm{a}}$ \\
\hline Creatinine, $\mu M$ & $76.5 \pm 12.1$ & $83.5 \pm 15.0$ & $93 \pm 12.5^{\mathrm{a}}$ \\
\hline \multicolumn{4}{|l|}{ Medications, $\%$} \\
\hline Statins & 0 & 85 & 83 \\
\hline$\beta$-blocker & 0 & 70 & 15 \\
\hline Diuretics & 0 & 65 & 18 \\
\hline ACEI/ARB & 0 & 32 & 75 \\
\hline Calcium blocker & 0 & 20 & 10 \\
\hline Aspirin & 0 & 90 & 75 \\
\hline Clopidogrel & 0 & 40 & 45 \\
\hline Insulin & 0 & 0 & 10 \\
\hline Metformin & 0 & 0 & 70 \\
\hline Sulfonylurea & 0 & 0 & 35 \\
\hline$\alpha$-glucosidase inhibitor & 0 & 0 & 20 \\
\hline
\end{tabular}

${ }^{a} p<0.05$ versus healthy volunteers. Reported $p$-values are from one-way analysis of variance.

ACEI, angiotensin-converting enzyme inhibitor; ARB, angiotensin receptor blocker; BMI, body mass index; BP, blood pressure; CAD, coronary artery diseases; CRP, C-reactive protein; HDL, high-density lipoprotein; LDL, low-density lipoprotein; SD, standard deviation.

participate in the pathological effects, very similar to the role of heterodimer of TLR4-TLR6 and CD36 in sterile inflammation induced by ox-LDL (57), which deserves to be explored in further experiments.

p38 MAPK and NF- $\kappa$ B pathways are associated with inflammation, apoptosis, oxidative stress, and angiogenesis. p38/MAPK and NF- $\kappa$ B pathways were shown to be involved in the impaired angiogenesis by $\operatorname{CD} 36(48,68)$. Consistent with these results, we found that both phosphor-p38 expression and activity of NF- $\kappa \mathrm{B}$ were significantly increased after incubation of EPCs with ox-HDL, and pretreatment with p38 or NF- $\kappa \mathrm{B}$-specific inhibitor could significantly attenuate the inhibitory effects induced by ox-HDL in EPCs, which thus further confirmed the involvements of p38/MAPK and NF- $\kappa$ B pathways in ox-HDL-induced pathological effects on EPCs. Xie et al. showed that testicular orphan nuclear receptor 4 (TR4) modulated foam cells' CD36 expression (73), and the expression of TR4 was linked with activation of MAPK pathway (25); so, it was reasonable to speculate that ox-HDL activated $\mathrm{p} 38 \mathrm{MAPK}-\mathrm{NF}-\kappa \mathrm{B}$ pathway, then increased TR4 expression, and, eventually, induced CD36 mRNA and protein expression via a transcriptional regulation, which deserved confirmation through further experiments.

Angiogenesis is tightly regulated by balancing the expression of factors that promote as well as inhibit the formation of blood vessels. TSP-1 and VEGF are two major players influencing angiogenesis. VEGF promotes while
TSP-1 inhibits angiogenesis. TSP-1, an extracellular matrix protein, serves as a ligand for CD36. TSP-1 binding to CD36 could mediate a series of signaling cascade to inhibit angiogenesis and induce endothelial cell apoptosis (28). In this study, we showed that TSP-1 but not VEGF was involved in the ox-HDL-induced pathological effects on EPCs in a hypoxic environment. TSP-1 binding to CD36 may, therefore, form a vicious cycle and amplify such effects of oxHDL on EPCs. In addition to the interaction between TSP-1 and VEGF-related signal pathway, the cholesterol efflux decreased by ox-HDL might also directly or indirectly participate in EPCs' angiogenesis, which might be similar to the SR-BI's sensing pattern of plasma membrane cholesterol movement $(42,50)$. It could be inferred that ox-HDL decreased the cholesterol efflux of EPCs, which would lead to the modification of CD36-colocalized lipid microdomain on the cell surface composed of sphingomyelin and caveolin-1 $(40,44)$ and activation of the intracellular signal pathways, and, eventually, changed the angiogenesis of EPCs.

Although TBARS assay could not represent the ox-HDL levels in vivo completely, our study still uses it to measure lipid peroxidation for the following reasons: First, only carbonyls resulting from lipid peroxidation (malondialdehyde [MDA]) covalently modify lipid-free apoA-I and inhibit its ability to promote cellular cholesterol efflux by the ABCA1 pathway, not other kinds of carbonyls, including hydroxynonenal, glycolaldehyde, glyoxal, or methylglyoxal, which 
A

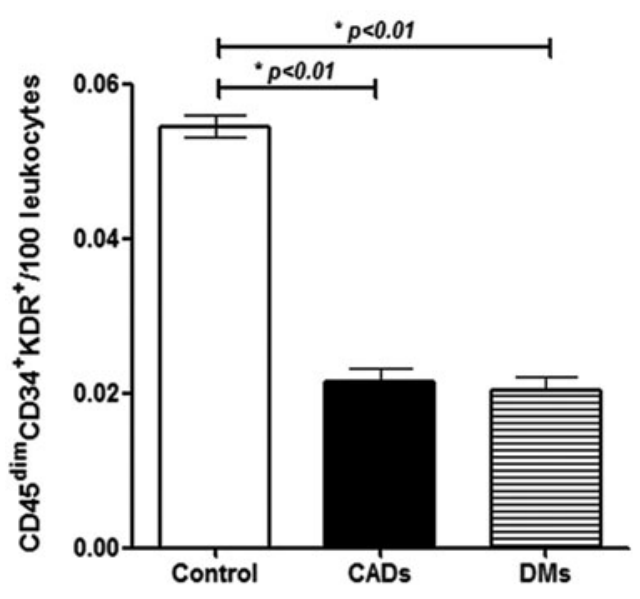

D

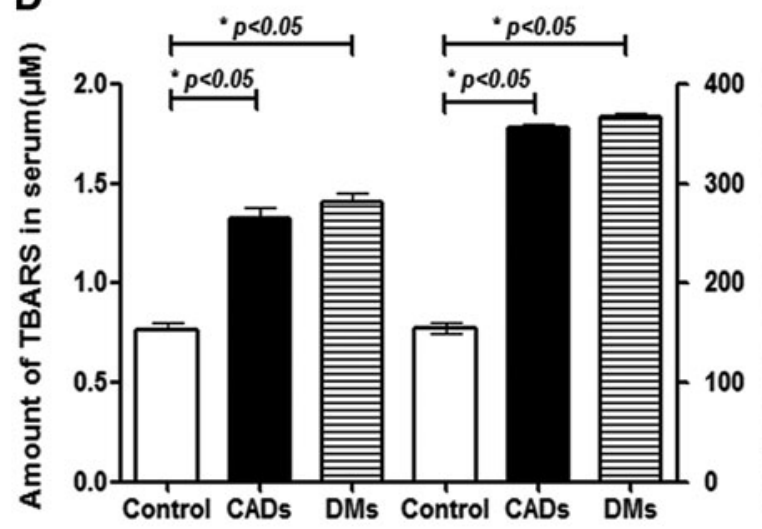

$\mathbf{F}$

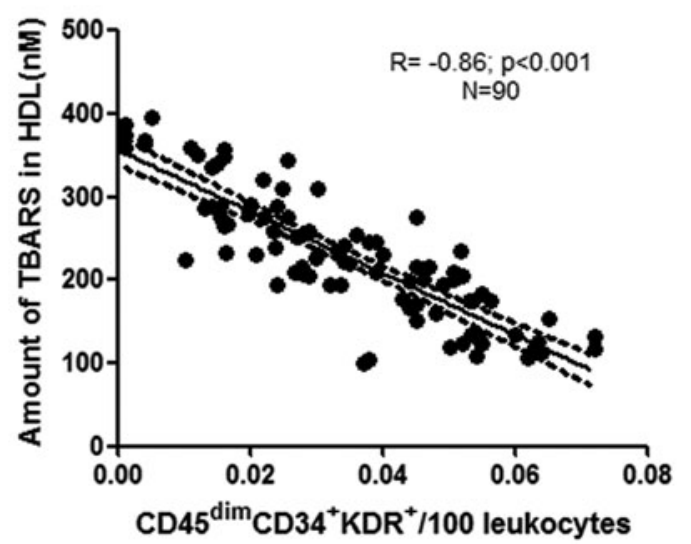

B

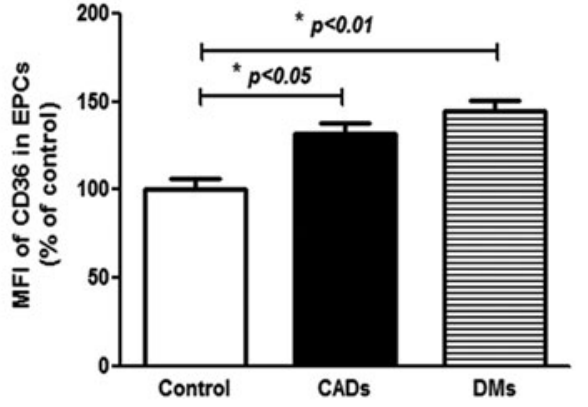

C

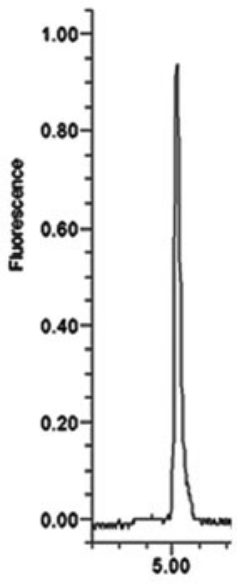

E

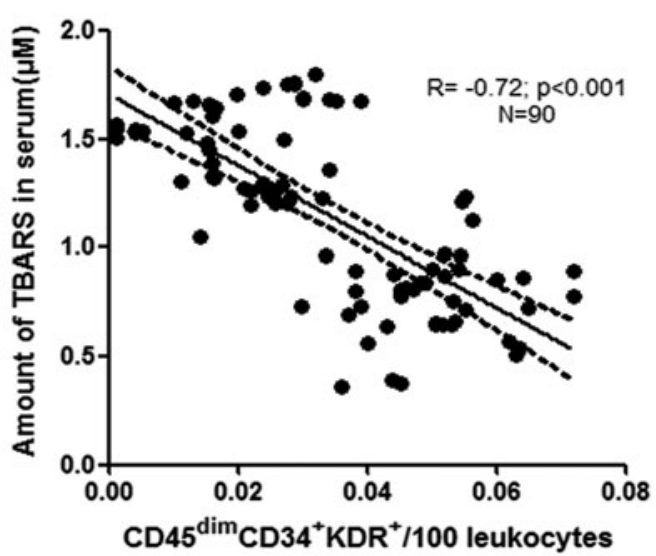

G

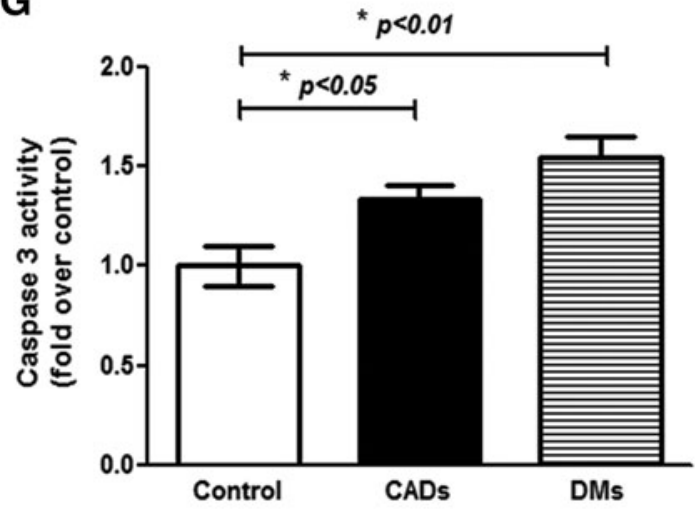

FIG. 7. Inverse correlation of ox-HDL and circulating EPCs. Decreased levels of circulating EPCs in patients with CAD or CAD and type 2 DM compared with those of healthy controls (A). The mean fluorescence intensities (MFI) of CD36 in EPCs were higher in patients with CAD (black column) or CAD with type $2 \mathrm{DM}$ (striped column) compared with those of healthy controls (unfilled column) (B). (C) The representative image of detection of MDA using HPLC. The MDA-thiobarbituric-acid complex was separated using reverse-phase high-performance liquid chromatography (RP-HPLC) on a Waters 2695 system (Waters, Inc.) coupled with a 474 fluorescence detector (excitation $=527 \mathrm{~nm}$, emission $=551 \mathrm{~nm}$ ) on a $250 \times 4.6 \mathrm{~mm}$ Dikma Diamonsil C18 (Dikma, Inc.) C18 column with $5 \mu \mathrm{m}$ particle size. The flow rate was $0.9 \mathrm{ml} / \mathrm{min}$, and the mobile phase was $40 \%$ phosphate buffer (10 mM, pH 5.8) with 60\% methanol. A standard curve was run at the start, middle, and end of each sample set using $1,1,3$, 3-tetraethoxypropane as a standard. Peak areas were determined using the Empower2 workstation (Waters, Inc.). A significant difference was seen between healthy controls and patients with CAD or type 2 DM about levels of TBARS in serum and HDL (D). Inverse correlation of circulating EPCs with levels of TBARS in serum (E) and HDL (F). Isolated serum HDL from healthy volunteers and CAD or CAD and type $2 \mathrm{DM}$ patients were added to the cultured EPCs at the concentration of $50 \mu \mathrm{g} / \mathrm{ml}$ for $24 \mathrm{~h}$, and then, the caspase 3 activity was assayed with a fluorescence detection kit. (G) $* p<0.05$ versus control. CAD, coronary artery diseases; DM, diabetes mellitus; MDA, malondialdehyde; thiobarbituric acid-reactive substances. 
implies a key role of MDA in the pathological process caused by ox-HDL (53); second, this assay has been widely used as a metrology of lipid peroxidation, and many reports explored lipid peroxidation by this assay $(22,61,69)$.

In summary, ox-HDL promotes apoptosis and inhibits migration, cholesterol efflux, and angiogenesis function of EPCs, which was consistent with the inverse correlation of ox-HDL and EPCs levels from the clinical study. Such effects were mainly mediated via scavenger receptor CD36 and P38/ MAPK, NF- $\kappa \mathrm{B}$, as well as TSP-1 signaling pathways. The negative effects of EPCs exerted by ox-HDL might represent potential and key pathological mechanisms for the development and progression of cardiovascular disease.

\section{Materials and Methods}

A Supplementary Materials and Methods section is available in Supplementary Data.

\section{Isolation and culture of EPCs}

EPCs were isolated from human whole blood provided by healthy volunteers as previously described (21). Briefly, human blood was directly diluted in EGM-2 supplemented with $15 \%$ fetal bovine serum, antibiotics, and cytokine cocktail (ratio of 1:4) in a T75 vented cap cell culture flask within less than $2 \mathrm{~h}$ after collection. Nonadherent cells were removed after overnight culture at $37^{\circ} \mathrm{C}, 5 \% \mathrm{CO}_{2}$ in humidified atmosphere by washing thrice with excess prewarmed $37^{\circ} \mathrm{C}$ phosphate-buffered saline (PBS) before adding new prewarmed $37^{\circ} \mathrm{C}$ EGM-2. Thereafter, media were changed every 4 days and the cultures were monitored daily for the emergence of small compact colonies. When these expanded EPC became confluent, they were trypsinized, counted, and replated in T75 flasks. Such cells were identified and characterized using an Olympus IX51 inverted microscope with Micropublisher 5.0 RTV (Q-Imaging corporation) for 1,1'dioctadecyl-3,3,3',3'-tetramethylindocarbocyanine-labeled ac-LDL (DiI-ac-LDL)/FITC-labeled Ulex europaeus agglutinin-I (FITC-UEA-I) double-positive cells, while DAPI was used to stain the nuclei. In addition to the image captured by microscopy, the expressions of surface markers and eNOS were also investigated with flow cytometry and Western blot separately. Human umbilical vein endothelial cells and monocytic THP-1 cells (ATCC) served as relative positive and negative controls, respectively.

\section{Preparation and oxidation of HDL}

Blood samples for HDL preparation were taken from healthy volunteers. Informed consent was obtained from all volunteers. HDL was obtained from freshly isolated human plasma by cumulative flotation ultracentrifugation, then dialyzed against PBS, and stored in EDTA $(100 \mu M)$ at $4^{\circ} \mathrm{C}$. Before use, EDTA was removed by extensive dialysis against PBS. HDL $(0.04 \mathrm{mg}$ protein $/ \mathrm{ml})$ was oxidized $\left(37^{\circ} \mathrm{C}\right)$ using copper sulfate $(0.5 \mu M$ final concentration $)$ for $2 \mathrm{~h}$ as previously described (24). Such a setting was chosen to achieve maximum levels of PC 16:0/18:2-OOH and 18:0/18:2-OOH in ox-HDL described in the literature (24). After addition of EDTA $(100 \mu M)$ to sequester copper ions, the HDL preparation was extensively dialyzed against PBS. The degree of oxidation was determined by measuring the amount of
TBARS (34). Value for TBARS in ox-HDL was $4.5 \mathrm{n} M$ malonyldialdehyde/mg protein. In addition to TBARS, electrophoresis mobility was also used to evaluate the lipid peroxidation of HDL. The electrophoresis mobility copperoxidized ox-HDL was $0.7 \mathrm{~cm}$ compared with naïve HDL's $0.35 \mathrm{~cm}$, which was slightly lower than in vivo HDL oxidation in patients with type 2 diabetes (56). Fluorescent labeling of ox-HDL was performed as previously described with Dil (2).

\section{Stable knockdown of CD36 in EPCs}

EPCs in which CD36 expression was stably silenced were generated by the stable transfection of EPCs using shRNA targeted to CD36. The shRNA plasmid was transfected into EPCs using Amaxa Nucleofector with Human CD34 Cell Nucleofector Kit with U08 pulsing parameters $(10,36)$. The efficiency of siRNA transfection was greater than $70 \%$. Positive clones were selected using puromycin. After expansion of these clones, CD36 silencing was assessed using real time PCR (RT-PCR) and Western blot.

\section{Apoptosis assay}

Apoptosis of EPCs was explored with Roche's AnnexinV-FLUOS Staining Kit and Sigma Caspase 3 Fluorimetric Assay Kit according to the manufacturer's instructions.

\section{EPCs migration assay}

The migratory function of EPCs was investigated by transwell and scratch wound-healing assay as previously described (59).

\section{EPCs tube formation assay}

In vitro tube formation assay was performed with $\mathrm{CHE}$ MICON In Vitro Angiogenesis Assay Kit (Millipore) according to the manufacturer's instructions. In brief, EC Matrix gel solution was thawed at $4^{\circ} \mathrm{C}$ overnight, then mixed with $10 \times$ EC Matrix diluent buffer, and placed in a 96-well plate at $37^{\circ} \mathrm{C}$ for $1 \mathrm{~h}$ to enable the matrix solution to solidify. EPCs were harvested; then, $1 \times 10^{4}$ cells were placed on matrix solution with complete medium and incubated at $37^{\circ} \mathrm{C}$ for $8 \mathrm{~h}$. Tube formation was inspected under an inverted light microscope $(100 \times)$. Six representative fields were taken and the total number of tubes, branching points, and the length of the tubes as well as the sum of the lengths of all tubes were calculated for each well (1).

\section{Determination of ROS generation}

Changes in intracellular ROS levels were determined by measuring the oxidative conversion of cell-permeable $2^{\prime}, 7^{\prime}$ dichlorofluorescein diacetate (DCFH-DA) to fluorescent dichlorofluorescein (DCF). After stimulation for $24 \mathrm{~h}$, the cells were washed and incubated with DCFH-DA at $37^{\circ} \mathrm{C}$ for 20 min. The DCF fluorescence distribution was recorded by a fluorescence microscope at an excitation wavelength of $488 \mathrm{~nm}$ and an emission wavelength of $525 \mathrm{~nm}$, and then analyzed with ImageJ (NIH) (54).

\section{Transplantation of EPCs}

In order to prove the effective incorporation of cultured EPCs into the neovascularization after inducing unilateral 
hind limb ischemia, such cells were labeled with a red fluorescent dye, PKH26GL as previously described (74) and injected $\left(1 \times 10^{6} / 100 \mu\right.$ l saline per mice $)$ into the tail vein using a 30-gauge needle.

\section{Immunofluorescence analysis of blood vessels in gastrocnemius muscles}

Vascularity of gastrocnemius muscles from nude mice was assessed by in situ fluorescent staining using an endothelial cellspecific marker, BS-1 lectin conjugated to FITC as previously described (26). After anesthesia, the hind limbs were perfused with FITC-BS-1 lectin by a direct cardiac injection. Fifteen minutes later, the animals were sacrificed and the gastrocnemius muscles were harvested and fixed in $4 \%$ paraformaldehyde (PFA). After fixation, samples were embedded in optimum cutting temperature compound for frozen sectioning. The images were recorded using a computer-assisted Olympus fluorescence microscope with a digital camera DP71 (Olympus IX51; Olympus, Inc.) and analyzed with ImageJ (NIH).

\section{Angiogenesis, blood flow, and functional scoring evaluation of ischemic hind limbs}

Twenty four hours after the surgery, serum-free medium or EPCs were injected into the tail vein at $1 \times 10^{6}$ cells/mouse. On postoperative day 14 , mice were anesthetized and a polyethylene catheter was inserted into the aorta, through which a contrast medium (barium sulfate, $0.5 \mathrm{~g} / \mathrm{ml}$ ) was injected. Angiography was then assessed by a high-definition digital X-ray system (MX-20; Faxitron). Two investigators blinded to the treatment protocol used a $1 \times 1-\mathrm{cm}$ grid overlay to count the number of vessels that transected a grid to obtain a quantitative measurement of the density of collateral vessels (angioscore) in the medial thigh region. Capillary density in the gastrocnemius muscle was assessed by immunofluorescence using rat anti-mouse CD31 antibody. Vessel density and capillary density were analyzed as previously described (14). Briefly, the number of capillaries was counted and averaged in 10 random microscopic fields from three independent cross-sections of the adductor muscle in each animal $(n=8)$, and then, capillary density was expressed as the number of capillaries per high-power field $(400 \times)$. Blood flow in the hind limb was measured just after the surgery and at day 14 using PeriFlux Laser Doppler Perfusion Measurement (LDPM) unit (Perimed) as previously described (41). In addition to the blood flow, mice were also examined for hind limb function at day 14 after induction of ischemia. Functional grading was performed with a standardized mouse limb ischemia grading scale according to a previous report (Supplementary Table S1) (72).

\section{Real-time quantitative PCR analysis}

Total RNA was extracted from cells using Trizol solution. The first-strand cDNA synthesis was performed using the 1st Strand cDNA Synthesis Kit. Real-time PCR was performed using SYBR Green PCR Master Mix iQ and Bio-rad CFX Connect real-time PCR System, according to the manufacturer's protocols. The PCR conditions were as follows: $30 \mathrm{~s}$ at $95^{\circ} \mathrm{C}$, followed by two-step PCR: $95^{\circ} \mathrm{C}$ for $15 \mathrm{~s}$ and $60^{\circ} \mathrm{C}$ for $30 \mathrm{~s}$ for 40 cycles with fluorescence monitoring at the end of each elongation step. Primers are in Supplementary Table S2.
Relative mRNA expression of target genes was calculated with the comparative threshold cycle method. All target sequences were normalized to GAPDH in multiplexed reactions performed in duplicate.

\section{Western blot analysis}

Cells were washed twice with cold PBS and lysed in protein extract buffer at $4^{\circ} \mathrm{C}$ for $30 \mathrm{~min}$. The lysates were centrifuged at $14,000 \mathrm{~g}, 4^{\circ} \mathrm{C}$, for $10 \mathrm{~min}$. The supernatant was then collected and stored at $-80^{\circ} \mathrm{C}$ until use. Samples were separated on $12 \%$ SDS-PAGE and transferred to a polyvinylidene difluoride membrane. The membrane was blocked with $5 \%$ nonfat milk, then incubated with primary antibody overnight at $4^{\circ} \mathrm{C}$, and exposed to a secondary antibody for $1 \mathrm{~h}$ at room temperature. The membranes were then washed and visualized by enhanced chemiluminescence detection reagents. The signal intensity of blotting was normalized to the signal of the corresponding total protein. Relative intensities of protein bands were analyzed by Image Pro Plus software.

\section{Hypoxic culture and enzyme-linked immunosorbent assay}

In order to maximally mimic the in vivo environment for EPCs injected into the nude mice with unilateral hind limb ischemia, the cells were cultured in a Plas-Labs chamber maintained at $1 \%$ oxygen (assessed by an Alpha Omega Oxygen Analyzer) at $37^{\circ} \mathrm{C}$. Cell medium was collected after stimulation and centrifuged at $4000 \mathrm{~g}$ in $4^{\circ} \mathrm{C}$ for $10 \mathrm{~min}$. The stimulation and collection were performed either immediately on removal from hypoxia or under hypoxic conditions in order to minimize re-oxygenation effects. Collected supernatant was stored at $-80^{\circ} \mathrm{C}$ until use. Release of TSP-1 and VEGF by EPCs in a hypoxic environment was measured by an enzyme-linked immunosorbent assay (ELISA) according to the manufacturer's instructions (R\&D systems).

\section{Nuclear protein preparation and EMSA of $N F-\kappa B$}

Nuclear extracts were prepared by washing cells twice with cold PBS, resuspending them in $400 \mu$ cold lysis buffer, and incubation for $15 \mathrm{~min}$ on ice with occasional vortexing to obtain complete cell lysis and release of nuclei. The tubes were centrifuged at $13,400 \mathrm{~g}$ for $1 \mathrm{~min}$; supernatant was removed completely; and remaining nuclei were resuspended in $25 \mu \mathrm{l}$ of cold nuclear extraction buffer, incubated for $30 \mathrm{~min}$ on ice, and centrifuged at 13,400 $g$ for $5 \mathrm{~min}$. Supernatant containing the soluble nuclear proteins was collected in tubes and stored at $-80^{\circ} \mathrm{C}$ until use. Equal protein amounts of the extracts $(10 \mu \mathrm{g})$ were used in experiments. The detection of the activated NF- $\kappa \mathrm{B}$ in the nuclei of unstimulated and stimulated cells was completed by using a digoxigeninlabeled EMSA kit according to the manufacturer's protocol. The probe sequence of NF- $\kappa \mathrm{B}$ was 5-AGT TGAGGGGA CTTTCCCAGGC-3.

\section{Flow cytometry quantification of circulating EPC following the ISHAGE gating strategy}

EPC were quantified using the following approach according to a previous study (52): Blood was drawn into EDTA collection tubes, and then transported into the laboratory within $2 \mathrm{~h}$. FcR-blocking antibody was added and 
incubated for $10 \mathrm{~min}$. All staining procedures were performed on ice. Whole-blood samples $(1 \mathrm{ml})$ were incubated with CD45, KDR, and CD34. The samples were lysed for removal of red blood cells before flow cytometry analysis in an FACSCalibur ${ }^{\mathrm{TM}}$ flow cytometer. Around 260,000 events in the gate R1 were acquired ( $\sim 300,000$ total events), and a minimum of $120 \mathrm{CD} 34^{+}$events were collected, according to recommendations. Intra-individual correlation was $r=0.94$ $(p<0.001)$, and inter-class correlation was $r=0.92$ $(p<0.001)$ for $\mathrm{CD} 45^{\mathrm{dim}} \mathrm{CD} 34^{+} \mathrm{KDR}^{+}$. Among the collected $\mathrm{CD} 45^{\mathrm{dim}} \mathrm{CD} 34{ }^{+} \mathrm{KDR}^{+} \mathrm{EPCs}$, the MFI of CD36 were compared between healthy control and patients with CADs using Flowjo software.

\section{Isolation of HDL and MDA detection with HPLC}

HDL was isolated as per gel filtration chromatography protocol previously described (17). In brief, $200 \mu \mathrm{l}$ serum was applied to two Superdex-200 gel filtration columns (10/300 GL; GE Healthcare) in series on an FPLC system (ÄKTA; GE Healthcare), using Tris buffer $(10 \mathrm{~m} M$ Tris, $0.15 \mathrm{~m} M$ $\mathrm{NaCl}, 1 \mathrm{~m} M$ EDTA, and $0.2 \% \mathrm{NaN} 3$ ) with a flow rate of $0.3 \mathrm{ml} / \mathrm{min}$. The eluate was collected using a fraction collector maintained at $4^{\circ} \mathrm{C}$, and then transferred to $-80^{\circ} \mathrm{C}$ refrigerator without the addition of exogenous antioxidants until the detection. After thawing the samples, measurements of MDA in terms of TBARS were performed in duplicate in each sample according to a modified protocol from a previous study (8) using Beyotime TBARS kit.

\section{Patient characteristics}

Patients with stable CAD, or CAD and type $2 \mathrm{DM}$ and agematched healthy volunteers (without cardiovascular risk factors) were recruited at the Department of Cardiology, Shanghai Changzheng Hospital from January 1, 2013 to August 2, 2014. Exclusion criteria included accompanying infectious, inflammatory or autoimmune disorders, advanced kidney or liver failure, neoplastic disorders, and a history of major surgery or trauma among the previous 3 months. Informed consent was obtained from all enrollers; the study protocol was approved by the Ethics Committee of the Second Military Medical University.

\section{Statistical analysis}

All data are expressed as means \pm standard errors. Differences between group means were determined by one-way analysis of variance followed by a Student-Newman-Keuls test. Linear regression analysis and nonparametric bivariate correlation (Spearman rank correlation coefficient) were used to correlate circulating EPC counts with cardiovascular risk factors. To identify independent determinants of EPC numbers, a multivariate linear regression analysis for various cardiovascular risk factors was performed. Statistical significance was assumed, if a null hypothesis could be rejected at $p \leq 0.05$. All statistical analysis was performed using GraphPad Prism 4 and SPSS for Windows 7.0.

\section{Acknowledgments}

The authors are especially grateful to Dr. Paula Arias, editors, and reviewers for their help in the preparation and revision of this article. They acknowledge the expertise and advice of Dr. Wen Xu from Nantong University; Dr. Caowu Tang and Professor Dahai Hu from Burn Center of Chinese PLA, Xijing Hospital, Fourth Military Medical University for helping with Laser Doppler scanning experiments; and Professor Jun Ma from Shanghai University of Traditional Chinese Medicine for helping with Cholesterol efflux assays. The study was supported by the National Natural Science Foundation of China (81130065, 81072981, 30971101, 31171130, 81473445, 81400336, and 30900528), Shanghai Pujiang Program (D-15), Key Program of Science and Technology Commission Foundation of Shanghai (10411956500), and Shanghai Projects of International Cooperation and Exchanges (10410701700).

\section{Author Disclosure Statement}

No competing financial interests exist.

\section{References}

1. Ahrens I, Domeij H, Eisenhardt SU, Topcic D, Albrecht M, Leitner E, Viitaniemi K, Jowett JB, Lappas M, Bode C, Haviv I, and Peter K. Opposing effects of monomeric and pentameric C-reactive protein on endothelial progenitor cells. Basic Res Cardiol 106: 879-895, 2011.

2. Al Gadban MM, Smith KJ, Soodavar F, Piansay C, Chassereau C, Twal WO, Klein RL, Virella G, LopesVirella MF, and Hammad SM. Differential trafficking of oxidized LDL and oxidized LDL immune complexes in macrophages: impact on oxidative stress. PLoS One 5: e12534, 2010.

3. Assinger A, Schmid W, Eder S, Schmid D, Koller E, and Volf I. Oxidation by hypochlorite converts protective HDL into a potent platelet agonist. FEBS Lett 582: 778-784, 2008.

4. Bai H, Liu BW, Deng ZY, Shen T, Fang DZ, Zhao YH, and Liu Y. Plasma very-low-density lipoprotein, low-density lipoprotein, and high-density lipoprotein oxidative modification induces procoagulant profiles in endogenous hypertriglyceridemia. Free Radic Biol Med 40: 1796-1803, 2006.

5. Barter P, Gotto AM, LaRosa JC, Maroni J, Szarek M, Grundy SM, Kastelein JJ, Bittner V, and Fruchart JC. HDL cholesterol, very low levels of LDL cholesterol, and cardiovascular events. N Engl J Med 357: 1301-1310, 2007.

6. Barter PJ, Nicholls S, Rye KA, Anantharamaiah GM, Navab M, and Fogelman AM. Antiinflammatory properties of HDL. Circ Res 95: 764-772, 2004.

7. Bujold K, Rhainds D, Jossart C, Febbraio M, Marleau S, and Ong H. CD36-mediated cholesterol efflux is associated with PPARgamma activation via a MAPK-dependent COX-2 pathway in macrophages. Cardiovasc Res 83: 457464, 2009.

8. Carbonneau MA, Peuchant E, Sess D, Canioni P, and Clerc M. Free and bound malondialdehyde measured as thiobarbituric acid adduct by HPLC in serum and plasma. Clin Chem 37: 1423-1429, 1991.

9. Chu LY, Ramakrishnan DP, and Silverstein RL. Thrombospondin-1 modulates VEGF signaling via CD36 by recruiting SHP-1 to VEGFR2 complex in microvascular endothelial cells. Blood 122: 1822-1832, 2013.

10. Diez M, Musri MM, Ferrer E, Barbera JA, and Peinado VI. Endothelial progenitor cells undergo an endothelial-tomesenchymal transition-like process mediated by TGFbetaRI. Cardiovasc Res 88: 502-511, 2010. 
11. Fadini GP, Sartore S, Albiero M, Baesso I, Murphy E, Menegolo M, Grego F, Vigili de Kreutzenberg S, Tiengo A, Agostini C, and Avogaro A. Number and function of endothelial progenitor cells as a marker of severity for diabetic vasculopathy. Arterioscler Thromb Vasc Biol 26: 2140-2146, 2006.

12. Febbraio M, Hajjar DP, and Silverstein RL. CD36: a class $\mathrm{B}$ scavenger receptor involved in angiogenesis, atherosclerosis, inflammation, and lipid metabolism. J Clin Invest 108: 785-791, 2001.

13. Ferretti G, Bacchetti T, Negre-Salvayre A, Salvayre R, Dousset N, and Curatola G. Structural modifications of HDL and functional consequences. Atherosclerosis 184: 17, 2006.

14. Foubert P, Silvestre JS, Souttou B, Barateau V, Martin C, Ebrahimian TG, Lere-Dean C, Contreres JO, Sulpice E, Levy BI, Plouet J, Tobelem G, and Le Ricousse-Roussanne S. PSGL-1-mediated activation of EphB4 increases the proangiogenic potential of endothelial progenitor cells. J Clin Invest 117: 1527-1537, 2007.

15. Francis GA. High density lipoprotein oxidation: in vitro susceptibility and potential in vivo consequences. Biochim Biophys Acta 1483: 217-235, 2000.

16. Girona J, LaVille AE, Sola R, Motta C, and Masana L. HDL derived from the different phases of conjugated diene formation reduces membrane fluidity and contributes to a decrease in free cholesterol efflux from human THP-1 macrophages. Biochim Biophys Acta 1633: 143-148, 2003.

17. Gordon SM, Deng J, Lu LJ, and Davidson WS. Proteomic characterization of human plasma high density lipoprotein fractionated by gel filtration chromatography. J Proteome Res 9: 5239-5249, 2010.

18. Hale JS, Li M, Sinyuk M, Jahnen-Dechent W, Lathia JD, and Silverstein RL. Context dependent role of the CD36thrombospondin-histidine-rich glycoprotein axis in tumor angiogenesis and growth. PLoS One 7: e40033, 2012.

19. Hamed S, Brenner B, Aharon A, Daoud D, and Roguin A. Nitric oxide and superoxide dismutase modulate endothelial progenitor cell function in type 2 diabetes mellitus. Cardiovasc Diabetol 8: 56, 2009.

20. Hofmann NA, Reinisch A, and Strunk D. Isolation and large scale expansion of adult human endothelial colony forming progenitor cells. J Vis Exp 1524, 2009.

21. Hofmann NA, Reinisch A, and Strunk D. Endothelial colony-forming progenitor cell isolation and expansion. Methods Mol Biol 879: 381-387, 2012.

22. Honma T, Tsuduki T, Sugawara S, Kitano Y, Ito J, Kijima R, Tsubata M, Nakagawa K, and Miyazawa T. Aging decreases antioxidant effects and increases lipid peroxidation in the Apolipoprotein E deficient mouse. J Clin Biochem Nutr 52: 234-240, 2013.

23. Huang CY, Lin FY, Shih CM, Au HK, Chang YJ, Nakagami H, Morishita R, Chang NC, Shyu KG, and Chen JW. Moderate to high concentrations of high-density lipoprotein from healthy subjects paradoxically impair human endothelial progenitor cells and related angiogenesis by activating Rho-associated kinase pathways. Arterioscler Thromb Vasc Biol 32: 2405-2417, 2012.

24. Hui SP, Taguchi Y, Takeda S, Ohkawa F, Sakurai T, Yamaki S, Jin S, Fuda H, Kurosawa T, and Chiba $H$. Quantitative determination of phosphatidylcholine hydroperoxides during copper oxidation of LDL and HDL by liquid chromatography/mass spectrometry. Anal Bioanal Chem 403: 1831-1840, 2012.
25. Huq MD, Gupta P, Tsai NP, and Wei LN. Modulation of testicular receptor 4 activity by mitogen-activated protein kinase-mediated phosphorylation. Mol Cell Proteomics 5: 2072-2082, 2006.

26. Jeong JO, Kim MO, Kim H, Lee MY, Kim SW, Ii M, Lee JU, Lee J, Choi YJ, Cho HJ, Lee N, Silver M, Wecker A, Kim DW, and Yoon YS. Dual angiogenic and neurotrophic effects of bone marrow-derived endothelial progenitor cells on diabetic neuropathy. Circulation 119: 699-708, 2009.

27. Jiang H, Liang C, Liu X, Jiang Q, He Z, Wu J, Pan X, Ren $\mathrm{Y}$, Fan M, Li M, and Wu Z. Palmitic acid promotes endothelial progenitor cells apoptosis via p38 and JNK mitogen-activated protein kinase pathways. Atherosclerosis 210: 71-77, 2010.

28. Jimenez B, Volpert OV, Crawford SE, Febbraio M, Silverstein RL, and Bouck N. Signals leading to apoptosisdependent inhibition of neovascularization by thrombospondin-1. Nat Med 6: 41-48, 2000.

29. Juliet PA, Hayashi $\mathrm{T}$, Iguchi $\mathrm{A}$, and Ignarro LJ. Concomitant production of nitric oxide and superoxide in human macrophages. Biochem Biophys Res Commun 310: 367-370, 2003.

30. Kashyap SR, Ioachimescu AG, Gornik HL, Gopan T, Davidson MB, Makdissi A, Major J, Febbraio M, and Silverstein RL. Lipid-induced insulin resistance is associated with increased monocyte expression of scavenger receptor CD36 and internalization of oxidized LDL. Obesity (Silver Spring) 17: 2142-2148, 2009.

31. Kaur S, Kumar TR, Uruno A, Sugawara A, Jayakumar K, and Kartha CC. Genetic engineering with endothelial nitric oxide synthase improves functional properties of endothelial progenitor cells from patients with coronary artery disease: an in vitro study. Basic Res Cardiol 104: 739-749, 2009.

32. Khaidakov M, Mitra S, Wang X, Ding Z, Bora N, Lyzogubov V, Romeo F, Schichman SA, and Mehta JL. Large impact of low concentration oxidized LDL on angiogenic potential of human endothelial cells: a microarray study. PLoS One 7: e47421, 2012.

33. Kim HM, Kim KJ, Moon JH, Lee HJ, Chae MK, Chang HJ, Kang ES, Cha BS, Lee HC, Kim YJ, and Lee BW. Association between EPCs count and rate of coronary revascularization in asymptomatic type 2 diabetic patients. Acta Diabetol 49: 413-420, 2012.

34. Kontush A, de Faria EC, Chantepie S, and Chapman MJ. Antioxidative activity of HDL particle subspecies is impaired in hyperalphalipoproteinemia: relevance of enzymatic and physicochemical properties. Arterioscler Thromb Vasc Biol 24: 526-533, 2004.

35. Li W, Febbraio M, Reddy SP, Yu DY, Yamamoto M, and Silverstein RL. CD36 participates in a signaling pathway that regulates ROS formation in murine VSMCs. $J$ Clin Invest 120: 3996-4006, 2010.

36. Liu Q, Xi Y, Terry T, So SP, Mohite A, Zhang J, Wu G, Liu X, Cheng J, Ruan KH, Willerson JT, and Dixon RA. Engineered endothelial progenitor cells that overexpress prostacyclin protect vascular cells. J Cell Physiol 227: 2907-2916, 2012.

37. Liu ZJ and Velazquez OC. Hyperoxia, endothelial progenitor cell mobilization, and diabetic wound healing. Antioxid Redox Signal 10: 1869-1882, 2008.

38. Marsche G, Furtmuller PG, Obinger C, Sattler W, and Malle E. Hypochlorite-modified high-density lipoprotein acts as a sink for myeloperoxidase in vitro. Cardiovasc Res 79: 187-194, 2008. 
39. Matsunaga T, Hokari S, Koyama I, Harada T, and Komoda T. NF-kappa B activation in endothelial cells treated with oxidized high-density lipoprotein. Biochem Biophys Res Commun 303: 313-319, 2003.

40. Mattern HM, Raikar LS, and Hardin CD. The effect of caveolin-1 (Cav-1) on fatty acid uptake and CD36 localization and lipotoxicity in vascular smooth muscle (VSM) cells. Int J Physiol Pathophysiol Pharmacol 1: 1-14, 2009.

41. Melero-Martin JM, De Obaldia ME, Kang SY, Khan ZA, Yuan L, Oettgen P, and Bischoff J. Engineering robust and functional vascular networks in vivo with human adult and cord blood-derived progenitor cells. Circ Res 103: 194202, 2008.

42. Mineo C and Shaul PW. Role of high-density lipoprotein and scavenger receptor B type I in the promotion of endothelial repair. Trends Cardiovasc Med 17: 156-161, 2007.

43. Mineo $\mathrm{C}$ and Shaul PW. PON-dering differences in HDL function in coronary artery disease. J Clin Invest 121: 2545-2548, 2011.

44. Mitsutake S, Zama K, Yokota H, Yoshida T, Tanaka M, Mitsui M, Ikawa M, Okabe M, Tanaka Y, Yamashita T, Takemoto H, Okazaki T, Watanabe K, and Igarashi Y. Dynamic modification of sphingomyelin in lipid microdomains controls development of obesity, fatty liver, and type 2 diabetes. J Biol Chem 286: 28544-28555, 2011.

45. Nagano Y, Arai H, and Kita T. High density lipoprotein loses its effect to stimulate efflux of cholesterol from foam cells after oxidative modification. Proc Natl Acad Sci U S A 88: 6457-6461, 1991.

46. Nuszkowski A, Grabner R, Marsche G, Unbehaun A, Malle E, and Heller R. Hypochlorite-modified low density lipoprotein inhibits nitric oxide synthesis in endothelial cells via an intracellular dislocalization of endothelial nitricoxide synthase. J Biol Chem 276: 14212-14221, 2001.

47. Podrez EA, Poliakov E, Shen Z, Zhang R, Deng Y, Sun M, Finton PJ, Shan L, Gugiu B, Fox PL, Hoff HF, Salomon $\mathrm{RG}$, and Hazen SL. Identification of a novel family of oxidized phospholipids that serve as ligands for the macrophage scavenger receptor CD36. J Biol Chem 277: 38503-38516, 2002.

48. Primo L, Ferrandi C, Roca C, Marchio S, di Blasio L, Alessio M, and Bussolino F. Identification of CD36 molecular features required for its in vitro angiostatic activity. FASEB J 19: 1713-1715, 2005.

49. Reinisch A, Hofmann NA, Obenauf AC, Kashofer K, Rohde E, Schallmoser K, Flicker K, Lanzer G, Linkesch W, Speicher MR, and Strunk D. Humanized large-scale expanded endothelial colony-forming cells function in vitro and in vivo. Blood 113: 6716-6725, 2009.

50. Saddar S, Mineo C, and Shaul PW. Signaling by the highaffinity HDL receptor scavenger receptor B type I. Arterioscler Thromb Vasc Biol 30: 144-150, 2010.

51. Sata M. Role of circulating vascular progenitors in angiogenesis, vascular healing, and pulmonary hypertension: lessons from animal models. Arterioscler Thromb Vasc Biol 26: 1008-1014, 2006.

52. Schmidt-Lucke C, Fichtlscherer S, Aicher A, Tschope C, Schultheiss HP, Zeiher AM, and Dimmeler S. Quantification of circulating endothelial progenitor cells using the modified ISHAGE protocol. PLoS One 5: e13790, 2010.

53. Shao B, Pennathur S, Pagani I, Oda MN, Witztum JL, Oram JF, and Heinecke JW. Modifying apolipoprotein A-I by malondialdehyde, but not by an array of other reactive carbonyls, blocks cholesterol efflux by the ABCA1 pathway. J Biol Chem 285: 18473-18484, 2010.

54. Shilo S, Roy S, Khanna S, and Sen CK. Evidence for the involvement of miRNA in redox regulated angiogenic response of human microvascular endothelial cells. Arterioscler Thromb Vasc Biol 28: 471-477, 2008.

55. Sirpal S. Myeloperoxidase-mediated lipoprotein carbamylation as a mechanistic pathway for atherosclerotic vascular disease. Clin Sci (Lond) 116: 681-695, 2009.

56. Sorrentino SA, Besler C, Rohrer L, Meyer M, Heinrich K, Bahlmann FH, Mueller M, Horvath $\mathrm{T}$, Doerries $\mathrm{C}$, Heinemann M, Flemmer S, Markowski A, Manes C, Bahr MJ, Haller H, von Eckardstein A, Drexler H, and Landmesser U. Endothelial-vasoprotective effects of highdensity lipoprotein are impaired in patients with type 2 diabetes mellitus but are improved after extended-release niacin therapy. Circulation 121: 110-122, 2010.

57. Stewart CR, Stuart LM, Wilkinson K, van Gils JM, Deng J, Halle A, Rayner KJ, Boyer L, Zhong R, Frazier WA, LacyHulbert A, El Khoury J, Golenbock DT, and Moore KJ. CD36 ligands promote sterile inflammation through assembly of a Toll-like receptor 4 and 6 heterodimer. Nat Immunol 11: 155-161, 2010.

58. Sumi M, Sata M, Miura S, Rye KA, Toya N, Kanaoka Y, Yanaga K, Ohki T, Saku K, and Nagai R. Reconstituted high-density lipoprotein stimulates differentiation of endothelial progenitor cells and enhances ischemia-induced angiogenesis. Arterioscler Thromb Vasc Biol 27: 813-818, 2007.

59. Sun C, Liang C, Ren Y, Zhen Y, He Z, Wang H, Tan H, Pan $\mathrm{X}$, and $\mathrm{Wu} \mathrm{Z}$. Advanced glycation end products depress function of endothelial progenitor cells via p38 and ERK 1/2 mitogen-activated protein kinase pathways. Basic Res Cardiol 104: 42-49, 2009.

60. Szmitko PE, Fedak PW, Weisel RD, Stewart DJ, Kutryk MJ, and Verma S. Endothelial progenitor cells: new hope for a broken heart. Circulation 107: 3093-3100, 2003.

61. Tanaka S, Miki T, Sha S, Hirata K, Ishikawa Y, and Yokoyama M. Serum levels of thiobarbituric acid-reactive substances are associated with risk of coronary heart disease. J Atheroscler Thromb 18: 584-591, 2011.

62. Tang Y, Vater C, Jacobi A, Liebers C, Zou X, and Stiehler M. Salidroside exerts angiogenic and cytoprotective effects towards human bone marrow derived endothelial progenitor cells via Akt/mTOR/p70S6K and MAPK signaling pathways. Br J Pharmacol 171: 2440-2456, 2014.

63. Tepper OM, Galiano RD, Capla JM, Kalka C, Gagne PJ, Jacobowitz GR, Levine JP, and Gurtner GC. Human endothelial progenitor cells from type II diabetics exhibit impaired proliferation, adhesion, and incorporation into vascular structures. Circulation 106: 2781-2786, 2002.

64. Terasaka N, Wang N, Yvan-Charvet L, and Tall AR. Highdensity lipoprotein protects macrophages from oxidized low-density lipoprotein-induced apoptosis by promoting efflux of 7-ketocholesterol via ABCG1. Proc Natl Acad Sci U S A 104: 15093-15098, 2007.

65. Thorne RF, Mhaidat NM, Ralston KJ, and Burns GF. CD36 is a receptor for oxidized high density lipoprotein: implications for the development of atherosclerosis. FEBS Lett 581: 1227-1232, 2007.

66. Thum T, Fraccarollo D, Thum S, Schultheiss M, Daiber A, Wenzel P, Munzel T, Ertl G, and Bauersachs J. Differential effects of organic nitrates on endothelial progenitor cells are determined by oxidative stress. Arterioscler Thromb Vasc Biol 27: 748-754, 2007. 
67. Tie G, Yan J, Yang Y, Park BD, Messina JA, Raffai RL, Nowicki PT, and Messina LM. Oxidized low-density lipoprotein induces apoptosis in endothelial progenitor cells by inactivating the phosphoinositide 3-kinase/Akt pathway. J Vasc Res 47: 519-530, 2010.

68. Triantafilou M, Gamper FG, Haston RM, Mouratis MA, Morath S, Hartung $\mathrm{T}$, and Triantafilou K. Membrane sorting of toll-like receptor (TLR)-2/6 and TLR2/1 heterodimers at the cell surface determines heterotypic associations with CD36 and intracellular targeting. J Biol Chem 281: 31002-31011, 2006.

69. Walter MF, Jacob RF, Bjork RE, Jeffers B, Buch J, Mizuno $\mathrm{Y}$, and Mason RP. Circulating lipid hydroperoxides predict cardiovascular events in patients with stable coronary artery disease: the PREVENT study. J Am Coll Cardiol 51: 1196-1202, 2008.

70. Wang JM, Isenberg JS, Billiar TR, and Chen AF. Thrombospondin-1/CD36 pathway contributes to bone marrowderived angiogenic cell dysfunction in type 1 diabetes via Sonic hedgehog pathway suppression. Am J Physiol Endocrinol Metab 305: E1464-E1472, 2013.

71. Werner N, Kosiol S, Schiegl T, Ahlers P, Walenta K, Link A, Bohm M, and Nickenig G. Circulating endothelial progenitor cells and cardiovascular outcomes. $N$ Engl J Med 353: 999-1007, 2005.

72. Westvik TS, Fitzgerald TN, Muto A, Maloney SP, Pimiento JM, Fancher TT, Magri D, Westvik HH, Nishibe T, Velazquez OC, and Dardik A. Limb ischemia after iliac ligation in aged mice stimulates angiogenesis without arteriogenesis. J Vasc Surg 49: 464-473, 2009.

73. Xie S, Lee YF, Kim E, Chen LM, Ni J, Fang LY, Liu S, Lin SJ, Abe J, Berk B, Ho FM, and Chang C. TR4 nuclear receptor functions as a fatty acid sensor to modulate CD36 expression and foam cell formation. Proc Natl Acad Sci U S A 106: 13353-13358, 2009.

74. Yoshida T, Komaki M, Hattori H, Negishi J, Kishida A, Morita I, and Abe M. Therapeutic angiogenesis by implantation of a capillary structure constituted of human adipose tissue microvascular endothelial cells. Arterioscler Thromb Vasc Biol 30: 1300-1306, 2010.

75. Zhou B, Ma FX, Liu PX, Fang ZH, Wang SL, Han ZB, Poon MC, and Han ZC. Impaired therapeutic vasculogenesis by transplantation of OxLDL-treated endothelial progenitor cells. J Lipid Res 48: 518-527, 2007.

Address correspondence to:

Prof. Chun Liang

Department of Cardiology

Shanghai Changzheng Hospital

Second Military Medical University

No. 415, Fengyang Road

Shanghai 200003

People's Republic of China

E-mail: chunliangliang@hotmail.com
Prof. Zonggui $W u$

Department of Cardiology

Shanghai Changzheng Hospital

Second Military Medical University

No. 415, Fengyang Road

Shanghai 200003

People's Republic of China

E-mail: wu_zonggui@yeah.net

Date of first submission to ARS Central, November 12, 2013; date of final revised submission, September 18, 2014; date of acceptance, October 13, 2014.

\begin{tabular}{|c|}
\hline 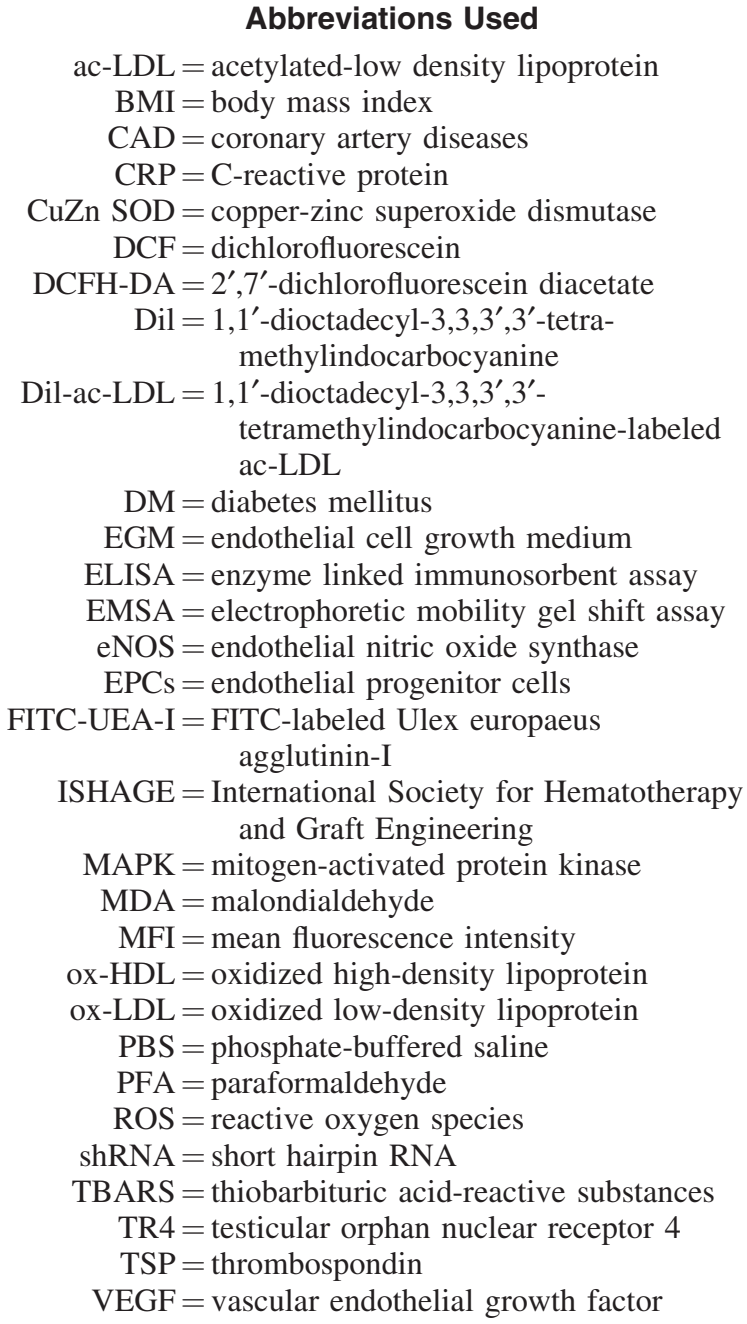 \\
\hline
\end{tabular}

